\title{
Cryptocurrency Market Contagion: Market Uncertainty, Market Complexity, and Dynamic Portfolios
}

\author{
Nikolaos Antonakakis ${ }^{\S, \dagger, *}$, Ioannis Chatziantoniou ${ }^{\S, \dagger}$, and David Gabauer ${ }^{\S, \ddagger}$

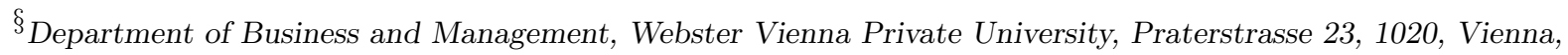 \\ Austria. \\ ${ }^{\dagger}$ Economics and Finance Subject Group, University of Portsmouth, Portsmouth Business School, Portland \\ Street, Portsmouth, PO1 3DE, United Kingdom. \\ ${ }^{\ddagger}$ Institute of Applied Statistics, Johannes Kepler University, Altenbergerstrae 69, 4040, Linz, Austria. \\ * Corresponding Author: Department of Business and Management, Webster Vienna Private University, \\ Praterstrasse 23, 1020, Vienna, Austria. Email: nikolaos.antonakakis@webster.ac.at. Tel: +43 126992934354.
}

\begin{abstract}
In this study, we employ a TVP-FAVAR connectedness approach in order to investigate the transmission mechanism in the cryptocurrency market. To this end, we concentrate on the top 9 cryptocurrencies by virtue of market capitalization and one market factor - based on 45 additional digital currencies - capturing the co-movements in the cryptocurrency market. The period of study spans between August 7, 2015 and May 31, 2018. We find that the dynamic total connectedness across several cryptocurrencies exhibits large dynamic variability ranging between $25 \%$ and $75 \%$. In particular, periods of high (low) market uncertainty correspond to strong (weak) connectedness. We show that these results could be explained on the basis of increased market uncertainty that is associated with periods of highly volatile prices. In addition, despite the fact that Bitcoin still influences the cryptcurrency market substantially, we note that, recently, Ethereum has become the number one net transmitting cryptocurrency. We further note that the market gradually becomes more complex considering our connectedness approach and that this might be attributed to the unique characteristics and possibilities inherent in the technology of each cryptocurrency. A simplified application concentrating on bivariate portfolios is indicative of potential hedging opportunities using dynamic hedge ratios and dynamic portfolio weights.
\end{abstract}

Keywords: Cryptocurrencies; Connectedness; Contagion; TVP-FAVAR.

JEL codes: C32; C5; G15 


\section{Introduction}

In recent years, cryptocurrencies have been in the spotlight of attention in financial markets all over the world. Bitcoin, which was the first currency of this technology to be invented, still remains the most popular digital currency; however, other alternatives such as Ethereum and Ripple are gaining pace, while in fact, during 2017, the market capitalization of all other digital currencies put together had equated the capitalization of Bitcoin (see, Bech and Garratt, 2017). Unequivocally, increased interest in cryptocurrencies rests largely upon the fact that their applications have the potential to determine future developments in many important aspects of real economic activity. For instance, Yermack (2018) puts forward the argument that the Bitcoin, although vulnerable to speculation, is widely being used as an alternative to fiat money, while, blockchain technology in general, might very well affect both central banking and corporate governance. Along these lines, some of the implications of blockchain technology on corporate governance are presented in Yermack (2017). Besides, monetary policy considerations and implications in the light of the upsurge of cryptocurrency markets have also been investigated by authors such as Fernández-Villaverde and Sanches (2016); Bordo and Levin (2017), as well as, Schilling and Uhlig (2018).

This study is primarily concerned with the role of digital currencies as tradable assets. That is, aside from its conventional use as an alternative to traditional fiat money, digital money appears to have recently gained much prominence owing also to its risk-hedging attributes. Authors such as Dyhrberg (2016); Bouri et al. (2017a); Urquhart and Zhang (2018), among others, assert that the Bitcoin might actually be employed for hedging against other asset classes such as shares of stock and currencies. Besides, Guesmi et al. (2018), provide evidence that (i) taking a short position in the price of Bitcoin effectively hedges risk initially assumed in various financial markets and (ii) including Bitcoin in portfolio diversification strategies greatly reduces the overall risk of the investment. However, speculation in cryptocurrency markets (see, for example, the recent fluctuations in the Bitcoin market) is conducive to periods of high volatility and uncertainty, which might in turn weaken the efficacy of the relevant portfolio diversification strategies (see, Cheah and Fry, 2015; Katsiampa, 2017).

Current relevant literature principally breaks down into studies that investigate speculation in the cryptocurrency market and studies that focus on the diversification benefits of cryptocurrencies. To be more explicit, the first strand mainly includes studies that investigate the argument that the market is not really efficient, but rather, reflects some speculative bubble; while the second strand, focuses mainly on the interaction of Bitcoin with other asset classes to the effect that more effective diversification strategies can be developed. Apparently, Bitcoin is the preferred cryptocurrency in most cases. Among this well-established wealth of literature, our study further investigates issues relating to both speculation and hedging, by concentrating on a rather new and, as of yet, scarce strand that involves the interaction across cryptocurrencies. As we explain in greater detail below, a few studies have reported that there may be discrepancies across cryptocurrency markets that deserve further investigation and in this regard, our study considers connectedness as a measure of cryptocurrency-heterogeneity. In effect, the evolution of total connectedness across cryptocurrencies could be explained by the extent to which economic agents assume cryptocurrency markets to be efficient. At the same time, net connectedness results imply that specific differences across popular cryptocurrencies might be conducive to new diversification opportunities.

In order to elaborate on the arguments put forward by the aforementioned strands of the literature, we dwell on specific academic articles that practically form the basis of our study. Starting with speculation and/or efficiency in the cryptocurrency market, Baur et al. (2018b) attest that, at one end of the scale, the Bitcoin market is rather uncorrelated with traditional financial markets, while at the other end of the spectrum, the market is subject to speculative investment. These results resonate with authors such as Fry and Cheah (2016); Corbet et al. (2017) and Katsiampa (2017). Furthermore, in a quite insightful analysis, Williamson et al. (2018) argues that contrary to traditional fiat money which is more likely than not a rational bubble - given that it practically derives its value from the mere fact that people accept it as a means of exchange, Bitcoin rather constitutes an irrational one; that is, if one takes into account its many drawbacks (e.g., upper limit in transactions volume, high transaction costs, price volatility). Some of the limitations of Bitcoin have also been emphasized by Dwyer (2015). Nonetheless, authors such as Corbet et al. (2018c) emphasize that existing literature is rather inconclusive in connection with cryptocurrencies being vulnerable to speculation (see, for instance Blau, 2018). This implies that discussion 
should essentially steer towards the efficiency of the cryptocurrency market and the ensuing question of whether the recorded levels of high price volatility are indeed the result of speculation or not. A rather detailed account of all aforementioned considerations is provided in the work of Corbet et al. (2018a).

Turning to cryptocurrency market efficiency, current evidence is ambiguous. On the one side, some authors provide evidence that the Bitcoin market is rather efficient (see, Urquhart, 2016; Nadarajah and Chu, 2017; Bariviera, 2017; Tiwari et al., 2018, among many others); whereas on the other, authors suggest that the market is not quite so (see, for instance Al-Yahyaee et al., 2018; Kristoufek, 2018; Jiang et al., 2018). In the meantime, authors such as Urquhart (2016); Caporale et al. (2018), as well as, Sensoy (2018) emphasize that the Bitcoin market is rather becoming more efficient over time. Elaborating on the high price volatility in the Bitcoin market, Berentsen et al. (2018) explain that most cryptocurrencies are by default decentralized with rather fixed supply, which practically implies that they are also more prone to high short-term price fluctuations. In this regard, we could argue that high volatility is relatively inherent in cryptocurrency markets. On a parallel note, and as far as speculation is concerned, evidence of the latter is emphasized in the work of $\mathrm{Li}$ and Wang (2017) who concentrate on the exchange rate between the Bitcoin and the USD. In addition, Katsiampa (2017) assesses several Bitcoin price volatility modelling approaches and reaches the conclusion that the best existing model is suggestive of high levels of speculation in the market. Most importantly, from the standpoint of economic agents, large and/or sudden price fluctuations, irrespective of whether they can be justified or not, might always be construed as the result of speculation in the market.

Turning to studies that concentrate on risk-hedging and portfolio diversification, it appears that most of these studies concentrate on Bitcoin not only because it was the first digital currency to be developed, but also, for the simple fact that it still exhibits the largest market capitalization. What is more, only few studies investigate the interaction between Bitcoin and other prevalent financial assets. For instance, Dyhrberg (2016) provides evidence that the Bitcoin can be used for hedging purposes against FTSE index shares. Bouri et al. (2017b) document that Bitcoin hedges effectively against Asia Pacific stocks. Investigating emerging stock markets, Guesmi et al. (2018) reach the conclusion that Bitcoin constitutes an effective diversifier even within a portfolio that already includes commodities such as gold or oil. Chan et al. (2018) illustrate Bitcoin's hedging usefulness vis-a-vis a number of stock indices; namely, Euro STOXX, Nikkei, Shanghai A-Sharpe, S\&P 500, as well as, the TSX Index. Furthermore, evidence of different characteristics between the Bitcoin, gold and the USD is presented in the work of Baur et al. (2018a). In a related study Selmi et al. (2018) show that the Bitcoin, similarly to gold, effectively mitigates portfolio risk that is related to the oil market. Additionally, Corbet et al. (2018c) suggest that cryptocurrencies exhibit effective diversification characteristics particularly for short-term investors. On a parallel note, Symitsi and Chalvatzis (2018) show that shares of technology companies affect Bitcoin in the short run, whereas, Bitcoin has a lagged impact both on fossil fuel and clean-energy companies. Nonetheless, existing literature rather neglects interaction across cryptocurrencies per se. Investigating the latter, would be quite instructive not only towards better understanding the different characteristics across these markets, but also, in order to attain an additional measure of market risk; that is, one that stems directly from contagion dynamics. To put differently, the fact that cryptocurrencies exhibit certain common features does not necessarily imply that there is no room for wide discrepancies that deserve further investigation as they might be useful even for diversification purposes. Drawing from existing literature, Gkillas and Katsiampa (2018) report that different cryptocurrencies exhibit different levels of risk, with Bitcoin and Litecoin being the least risky and Bitcoin Cash, the riskiest. Furthermore, Brauneis and Mestel (2018) stress out heterogeneity across cryptocurrency markets, by showing that efficiency is associated with market liquidity. In close relation to the above, Phillip et al. (2018) document that lower market capitalization results in larger variability which is supported by Wei (2018) who finds that volatility declines with increasing liquidity.

Following existing arguments relating to potential discrepancies, our study purports to confirm cryptocurrency heterogeneity by considering the spillovers across a large number of popular cryptocurrencies. Relevant evidence in this scarce, as of yet, strand of the literature that focuses on exploring linkages across different cryptocurrencies, comes from Corbet et al. (2018c) who show that Bitcoin, Ripple, as well as, Litecoin are highly correlated with each other but rather remote from other financial assets; a fact that renders these effective for portfolio diversification purposes. Besides, Fry and Cheah (2016) maintain that there are indeed spillovers from the Ripple to Bitcoin. Furthermore, in an interesting study regarding both the short-run and the long-run relationship between the Bitcoin and Altcoin markets, Ciaian et al. 
(2018) report that there exists interdependency between the two, while in fact, this relationship appears to be significantly stronger in the short-run.

With these in mind, the objectives of our study are (i) to capture spillovers across the cryptocurrencies of our sample and (ii) to provide new evidence that predicate upon the most relevant empirical model regarding net shock transmitters and receivers in the cryptocurrency market in the course of time. In this regard, we add to the relatively scarce strand of the literature that concentrates specifically on the interaction across cryptocurrencies. In particular, we investigate the network connectedness (i.e., in the spirit of Diebold and Yilmaz, 2014) across the returns of several cryptocurrencies in order to provide new evidence regarding cryptocurrency market contagion. As we discuss in greater detail in the sections that follow, for the period between August 7, 2015 and May 31, 2018, we consider the top 9 cryptocurrencies (i.e., by virtue of capitalization) and we also include a single cryptomarket factor in order to capture the main return co-movements in the cryptocurrency market (i.e., via a time-varying parameters principal component analysis TVP-PCA - which is based on 45 additional cryptocurrencies). Connectedness results are predicated upon a time-varying parameters factor augmented vector autoregressive (TVPFAVAR) model, from which we derive the requisite generalized forecast error variance decompositions (GFEVDs).

It would be instructive at this point to emphasize that given the dynamic nature of the analysis, the TVP framework that we employ adds further value to this study as it effectively addresses most of the problems inherent in the typical rolling-window dynamic approach, like the arbitrarily chosen window size, the loss of observations and the outlier sensitivity.

Main findings indicate that the dynamic total connectedness exhibits large dynamic variability ranging between $25 \%$ and $75 \%$. In point of fact, connectedness across cryptocurrencies can be anything from moderate to strong. However, it should also be noted that in early 2017 connectedness reaches a minimum and then gradually escalates before it reaches very high levels, especially after February 2018. Furthermore, we provide evidence that periods of high (low) market uncertainty typically correspond to strong (weak) connectedness. Considering the fact that this dynamic framework of analysis allows for identifying cryptocurrencies that assume either a net-receiving or a net-transmitting position, we find that (i) most cryptocurrencies may take on both positions over time, (ii) the Bitcoin remains a net transmitter of spillovers to other digital currencies almost throughout the period of study (i.e., with the exception of Ethereum and Ripple which transmit spillovers to Bitcoin starting in late 2017 and throughout 2018), and (iii), in recent years spillovers stemming from Ethereum to all other digital currencies have markedly intensified.

Apparently, following its recent high price volatility, Bitcoin rather assumes a net receiving role when contrasted with Ethereum. In addition, the emergence of Ethereum as a net transmitter of shocks to other cryptocurrencies is a key finding from a portfolio diversification standpoint as it paves the path for Ethereum's effectiveness for mitigating investment risk. On a final note, in order to provide further support for the arguments presented in the study, we proceed with a simplified hedging exercise. In particular, we construct bivariate dynamic portfolios and test whether the ensuing volatility reflected upon the respective hedge ratios within each portfolio can be mitigated or not. Results reveal that volatility within these portfolios significantly declines after the structural break in the dynamic total connectedness which occurred around August, 2017. To the best of our knowledge, this is the first effort in the literature to investigate hedging possibilities on the basis of a portfolio that comprises two cryptocurrencies; thus, adding further value to the contribution of the study.

The remainder of the study is organized as follows. In Section 2, we present the data and the empirical methods employed in the study. In Section 3, we illustrate the relevant findings and investigate the corresponding arguments. Section 4 summarizes main objectives and findings, provides suggestions for further research and concludes the study.

\section{$2 \quad$ Data and Methodology}

\section{$2.1 \quad$ Data}

Our dataset consists of daily data from cryptocurrencies with market capitalization above 5 million USD (547 coins and tokens). We obtain our data from CoinMarketCap. The period of analysis spans between 
August 7, 2015 and May 31, 2018 due to data availability. To be in line with the literature we have chosen the same variables as in Brauneis and Mestel (2018) except for Monacoin since it dropped to rank 79 and its data availability starts from June 1, 2018. Hence, we are analysing Bitcoin (BTC), Ethereum (ETH), Ripple (XRP), Dash (DASH), Litecoin (LTC), Monero (XMR), Nem/New Economy Movement (XEM), Stellar (XLM) and Bitshares (BTS). We generate a single market factor representing the comovement of the cryptomarket via a TVP-PCA based on 45 cryptocurrencies (all cryptocurrencies that are available after the 7th August 2015). Since the cryptocurrency prices are non-stationary we proceed our analysis with the cryptocurrency returns. Descriptive statistics presented in Table 1 point out that all series are significantly skewed, leptokurtic, and non-normally distributed. Additionally, all series are stationary, autocorrelated and exhibit ARCH errors. The highest unconditional correlation among all cryptocurrencies can be observed between Bitcoin and Litecoin.

[Insert Table 1 around here]

\subsection{Methodology}

\subsubsection{TVP-FAVAR Connectedness Approach}

In the spirit of Bernanke et al. (2005), we extend the time-varying parameter connectedness methodology outlined in Antonakakis and Gabauer (2017) by using the TVP-FAVAR model introduced by Koop and Korobilis $(2014)^{1}$. This model is quite flexible since it allows for (i) the VAR coefficients and their variances, (ii) the PCA loadings and their variances, as well as, (iii) the variances of the VAR and PCA error terms to vary over time.

We employ one market factor which is based on 45 cryptocurrencies using PCA to extract the main co-movements of the cryptocurrency market. According to the Bayesian information criterion (BIC), we are employing a TVP-FAVAR with one lag which can be written as,

$$
\begin{aligned}
\boldsymbol{z}_{t} & =\boldsymbol{\Phi}_{t} \boldsymbol{z}_{t-1}+\boldsymbol{\epsilon}_{t} & \boldsymbol{\epsilon}_{t} & \sim N\left(\mathbf{0}, \boldsymbol{S}_{t}\right) \\
\boldsymbol{x}_{t} & =\boldsymbol{\Lambda}_{t} \boldsymbol{f}_{t}+\boldsymbol{u}_{t} & \boldsymbol{u}_{t} & \sim N\left(\mathbf{0}, \boldsymbol{V}_{t}\right) \\
\operatorname{vec}\left(\boldsymbol{\Phi}_{t}\right) & =\operatorname{vec}\left(\boldsymbol{\Phi}_{t-1}\right)+\boldsymbol{\xi}_{t} & \boldsymbol{\xi}_{t} & \sim N\left(\mathbf{0}, \mathbf{\Xi}_{t}\right) \\
\operatorname{vec}\left(\boldsymbol{\Lambda}_{t}\right) & =\operatorname{vec}\left(\boldsymbol{\Lambda}_{t-1}\right)+\boldsymbol{v}_{t} & \boldsymbol{v}_{t} & \sim N\left(\mathbf{0}, \mathbf{\Upsilon}_{t}\right)
\end{aligned}
$$

where $\boldsymbol{z}_{t}=\left[\boldsymbol{y}_{t}, \boldsymbol{f}_{t}\right]^{\prime}$ and $\boldsymbol{\epsilon}_{t}$ are $(N+r) \times 1$ dimensional vectors, $\boldsymbol{x}_{t}$ and $\boldsymbol{u}_{t}$ are $M \times 1$ dimensional vectors and $\boldsymbol{\xi}_{t}$ and $\boldsymbol{v}_{t}$ are $(N+r)^{2} \times 1$ and $(M \cdot r)^{2} \times 1$ dimensional vectors. Furthermore, $\boldsymbol{S}_{t}$ and $\boldsymbol{\Phi}_{t}$ are $(N+r) \times(N+r)$ dimensional matrices, $\boldsymbol{\Xi}_{t}$ and $\boldsymbol{\Upsilon}_{t}$ are $(N+r)^{2} \times(N+r)^{2}$ and $(M \cdot r)^{2} \times(M \cdot r)^{2}$ dimensional matrices, $\boldsymbol{\Lambda}$ is an $M \times r$ dimensional component loading matrix and $\boldsymbol{V}_{t}$ is an $M \times M$ dimensional matrix.

Through the Wold representation theorem we can transform our TVP-FAVAR to a time-varying parameter factor-augmented vector moving average (TVP-FAVMA) by, $\boldsymbol{z}_{t}=\sum_{i=1}^{p} \boldsymbol{\Phi}_{i t} \boldsymbol{z}_{t-i}+\boldsymbol{\epsilon}_{t}=$ $\sum_{i=0}^{\infty} \boldsymbol{A}_{i t} \boldsymbol{\epsilon}_{t-i}$. The time-varying coefficients $\left(\boldsymbol{A}_{i t}\right)$ of the TVP-FAVMA model are the foundation of the connectedness approach by Diebold and Yilmaz (2014) that uses the generalized impulse response functions (GIRF), $\Psi_{i j t}^{g}$, and generalized forecast error variance decompositions (GFEVD), $\tilde{\phi}_{i j t}^{g}(J)$, developed by Koop et al. (1996) and Pesaran and Shin (1998). We apply the GIRFs since it doesn't restrict us to impose a structure on the error terms; which is an approach that seem to be more appropriate given the nature of the data.

Moreover, we are mainly interested in the GFEVD which can be interpreted as the variance share variable $i$ explains on variable $j$. Mathematically, it can be written as follows,

$$
\tilde{\phi}_{i j t}^{g}(J)=\frac{\sum_{t=1}^{J-1} \Psi_{i j t}^{2, g}}{\sum_{j=1}^{N} \sum_{t=1}^{J-1} \Psi_{i j t}^{2, g}}
$$

\footnotetext{
${ }^{1}$ Explaining the multivariate Kalman Filter into detail is beyond the scope of this study. Hence, interested readers are referred to Koop and Korobilis (2014). In our study, the VAR prior is based on result of a constant VAR estimation on the first 200 days, the PCA prior is based on the results of a constant PCA estimation on the first 200 days and all forgetting factors are set equal to 0.99 . This value has proven to lead to a good forecasting performance as shown in the aforementioned study.
} 
with $\sum_{j=1}^{N} \tilde{\phi}_{i j t}^{N}(J)=1$ and $\sum_{i, j=1}^{N} \tilde{\phi}_{i j t}^{N}(J)=N$. Based on the GFEVD, we construct the total connectedness index (TCI) representing the interconnectedness of the network, formulated by

$$
C_{t}^{g}(J)=\frac{\sum_{i, j=1, i \neq j}^{N} \tilde{\phi}_{i j t}^{g}(J)}{\sum_{i, j=1}^{N} \tilde{\phi}_{i j t}^{g}(J)} * 100 .
$$

In addition, we are interested in the spillovers of variable $i$ TO (FROM) all others $j$, representing the total directional connectedness TO (FROM) others defined as

$$
C_{i \rightarrow j t}^{g}(J)=\frac{\sum_{j=1, i \neq j}^{N} \tilde{\phi}_{j i t}^{g}(J)}{\sum_{j=1}^{N} \tilde{\phi}_{j i t}^{g}(J)} * 100 \quad\left(C_{i \leftarrow j t}^{g}(J)=\frac{\sum_{j=1, i \neq j}^{N} \tilde{\phi}_{i j t}^{g}(J)}{\sum_{i=1}^{N} \tilde{\phi}_{i j t}^{g}(J)} * 100\right)
$$

The difference between the total directional connectedness TO others and FROM others results in the NET total directional connectedness:

$$
C_{i t}^{g}=C_{i \rightarrow j t}^{g}(J)-C_{i \leftarrow j t}^{g}(J)
$$

The NET total directional connectedness illustrates if variable $i$ is driving the network $\left(C_{i t}^{g}>0\right)$ or is driven by the network $\left(C_{i t}^{g}<0\right)$.

Finally, we break down the NET total directional connectedness even further to examine the bidirectional relationships by computing the net pairwise directional connectedness (NPDC),

$$
N P D C_{i j}(H)=\left(\frac{\tilde{\phi}_{j i t}(H)-\tilde{\phi}_{i j t}(H)}{N}\right) * 100 .
$$

The NPDC identifies if variable $i$ is influencing variable $j$ more or vice versa.

\subsubsection{DCC-GARCH t-Copula}

In a second step, we are interested in the co-movements of the analyzed cryptocurrencies and in the dynamic nature of portfolio weights and hedge ratios which are based on conditional variances and covariances. The conditional variances and covariances can be estimated applying a DCC-GARCH tCopula which is a very flexible multivariate GARCH model that is not running into problems analyzing a moderate number of assets. This model is based on Sklar (1959) theorem which allows to construct out of multiple marginal distribution one joint multivariate distribution. The extension from a static to a dynamic copula model was done by Patton (2006) who proved that the theorem still holds when dealing with conditional distributions. This can be written as follows:

$$
F\left(\boldsymbol{\epsilon}_{t} \mid \boldsymbol{h}_{t}\right)=C\left(F_{1}\left(\epsilon_{1 t} \mid h_{1 t}\right), \ldots, F_{n}\left(y_{N t} \mid h_{N t}\right)\right)
$$

where $\mathrm{C}$ is an N-dimensional Copula, $F_{i}$ is the conditional distribution of the $i$ th marginal density and $h_{i i t}$ is the conditional variance resulting from a univariate family GARCH $(1,1)$ model (Hentschel, 1995). In general, the family GARCH model can be written as follows:

$$
\begin{aligned}
z_{t} & =h_{t}^{0.5} \cdot \epsilon_{t} \\
h_{t}^{\lambda} & =\omega+\alpha h_{t-1}^{\lambda}\left(\left|z_{t-1}-\eta\right|-\gamma\left(z_{t-1}-\eta\right)\right)^{\delta}+\beta h_{t-1}^{\lambda}
\end{aligned}
$$

where $z_{t}$ illustrates the iid random variables. For the selection of every univariate GARCH model for each series we are applying the GARCH selection criterion by Antonakakis et al. (2018a).

Furthermore, a Student's t copula with the shape parameter $\eta$ and dynamic conditional correlation $\boldsymbol{R}_{t}$ 
is given by:

$$
c_{t}\left(u_{1 t}, \ldots, u_{N t} \mid \boldsymbol{R}_{t}, \nu\right)=\frac{f_{t}\left(F_{1}^{-1}\left(u_{1} \mid \nu\right), \ldots, F_{N}^{-1}\left(u_{N} \mid \nu\right) \mid \boldsymbol{R}_{t}, \nu\right)}{\prod_{i=1}^{N} f_{i}\left(F_{i}^{-1}\left(u_{i} \mid \nu\right) \mid \nu\right)}
$$

where $u_{i t}=F_{i}$ representing the Probability Integral Transformation (PIT) of each series by its conditional distribution $F_{i t}$. For $\boldsymbol{R}_{t}$ we follow the proposition of Engle (2002) which is defined by:

$$
\boldsymbol{H}_{t}=\boldsymbol{D}_{t} \boldsymbol{R}_{t} \boldsymbol{D}_{t}
$$

where $\boldsymbol{D}_{t}=\operatorname{diag}\left(h_{11 t}^{0.5}, \ldots, h_{N N t}^{0.5}\right)$ is the conditional variances resulting from the family GARCH first step estimation. $\boldsymbol{H}_{t}$ is an $N \times N$ matrix where the diagonal elements are conditional variances, $h_{i i t}$, and off-diagonal elements are conditional covariances, $h_{i j t} \forall i \neq j$. To achieve that $\boldsymbol{R}_{t}$ is positive definite, we create a proxy process $\boldsymbol{Q}_{t}$,

$$
\boldsymbol{Q}_{t}=(1-a-b) \overline{\boldsymbol{Q}}+a \boldsymbol{z}_{t-1} \boldsymbol{z}_{t-1}^{\prime}+b \boldsymbol{Q}_{t-1}
$$

where $\overline{\boldsymbol{Q}}$ is the unconditional variance of the standardized residuals $\boldsymbol{z}_{t}$ and $a+b<1$ are imposed to ensure stationarity and positive definiteness of $\boldsymbol{Q}_{t}$. Rescaling $\boldsymbol{Q}_{t}$ results in the dynamic conditional correlations $\boldsymbol{R}_{t}$,

$$
\boldsymbol{R}_{t}=\operatorname{diag}\left(\boldsymbol{Q}_{t}\right)^{-1 / 2} \boldsymbol{Q}_{t} \operatorname{diag}\left(\boldsymbol{Q}_{t}\right)^{-1 / 2} .
$$

The dynamic conditional correlations are used to identify if the co-movements of cryptocurrencies have increased over the studied period.

\subsubsection{Dynamic Portfolio Weights}

In the final step, we are interested in hedging and portfolio techniques. Thus, we are calculating dynamic optimal portfolio weights a la Kroner and Ng (1998) and dynamic hedge ratios a la Kroner and Sultan (1993) which are based on the conditional variance and covariances of the DCC-GARCH t-Copula.

The portfolio weights, $w_{i j t}$, between cryptocurrency $i$ and $j$ are calculated as follows

$$
w_{i j t}=\frac{h_{j j t}-h_{i j t}}{h_{i i t}-2 h_{i j t}+h_{j j t}} .
$$

where $w_{i j t}$ could be above one or below zero. To overcome this disadvantage, we impose the following restrictions:

$$
w_{i j t}= \begin{cases}0 & \text { if } w_{i j t}<0 \\ w_{i j t} & \text { if } 0 \leq w_{i j t} \leq 1 \\ 1 & \text { if } w_{i j t}>1\end{cases}
$$

$w_{i j t}$ can be interpreted as the weight of asset $i$ in a 1 USD portfolio based on two assets $i$ and $j$ at time $t$. The second weight regarding asset $j$ is $w_{j i t}=\left(1-w_{i j t}\right)$.

\subsubsection{Dynamic Hedge Ratio}

Hedge ratios determine the costs of hedging a 1 USD long position in asset $i$ with a $\beta_{i j t}$ USD short position in asset $j$. This can be calculated by

$$
\beta_{i j t}=\frac{h_{i j t}}{h_{j j t}} .
$$

This implies that higher conditional variances lead to lower long position hedging costs whereas an increase in the conditional covariances will increase the long position hedging costs. 


\subsubsection{Hedging Effectiveness}

Finally, the effectiveness of the hedging and portfolio techniques are evaluated using the hedging effectiveness measure a la Ederington (1979) which can be written as

$$
\begin{aligned}
r_{\beta} & =y_{i t}-\beta_{i j t} y_{j t} \\
r_{w} & =w_{i j t} y_{i t}+\left(1-w_{i j t}\right) y_{j t} \\
H E_{i} & =1-\frac{V\left(r_{w, \beta}\right)}{V\left(r_{\text {unhedged }}\right)}
\end{aligned}
$$

where $V\left(r_{\text {unhedged }}\right)$ illustrates the variance of the unhedged position of asset $i$ and $\operatorname{Var}\left(r_{w, \beta}\right)$ is the hedged portfolio variance either from the optimal dynamic hedge ratio or the optimal dynamic portfolio weight strategy. Since, $H E_{i}$ represents the percent reduction in the variance of the unhedged position. The higher $H E_{i}$ is the larger is the risk reduction. Since $H E_{i}$ is 1 minus a variance ratio which can be tested using an F-statistics as pointed out in Antonakakis et al. (2018b).

\section{Empirical Results}

In order to serve the specific objectives of the study; that is, to investigate the extent of connectedness across cryptocurrencies and to distinguish between net shock transmitters and receivers over time, in this Section, we concentrate only on the most relevant of the results. In particular, (i) we investigate the evolution of the TCI over time, (ii) we consider total net connectedness for each cryptocurrency and (iii) we dwell upon pairwise connectedness across cryptocurrencies.

\subsection{Dynamic Total Connectedness and Market Risk}

Starting with dynamic total connectedness, Figure 1 illustrates dynamic results for the TCI pertaining to the cryptocurrency market as a whole. The value of the index fluctuates over time within a broad range, spanning approximately between $25 \%$ and $75 \%$. This practically implies that connectedness across cryptocurrencies can be anything from moderate to very strong. Possible explanations for this large dynamic variability of the TCI could be related to the fact that the index is highly responsive to various events associated with the relevant markets. Reiterating a point made earlier, authors such as Berentsen et al. (2018) put forward the argument that cryptocurrencies are vulnerable to high short-term fluctuations given that they are decentralized with rather fixed supply. Furthermore, we note that towards the end of our sample period (i.e., starting in February 2018), more than $70 \%$ of the forecast error variance in all cryptocurrencies can be explained by cross connectedness.

\section{[Insert Figure 1 around here]}

Evidently, the period of analysis could be segregated into two distinct intervals. In particular, starting in Aug 2015, we note that connectedness follows a decreasing trend, reaching a minimum in early 2017; whereas the path, from that time forth, is clearly upward. Both of these intervals are also characterized by short-term fluctuations that most likely correspond to specific economic developments. Despite the fact that there may be a multitude of events affecting cryptocurrency returns (see, inter alia, Cheah et al., 2018; Corbet et al., 2018b) we maintain that in order to put our findings into perspective we need to consider the broader developments in the market for digital currencies.

In this regard, 2015 was a year marked by the release of Ethereum and the expansion of Ripple, which are currently second and third in line respectively, by virtue of market capitalization (see, among others, Ciaian et al., 2018). We argue that the establishment of these two important cryptocurrencies and the subsequent increase in their transactions' volume, has overall strengthened the potential for increased connectedness across currencies. It would be instructive at this point to note that, both Ethereum and Ripple should not be regarded as direct competitors of Bitcoin, as there exist considerable contrasts. In particular, although a thorough investigation of the precise differences between these cryptocurrencies falls beyond the scope of the present study, it should be emphasized that (i) Ethereum rather concentrates on smart-contracts and transaction-automations (Peng et al., 2018) and it does not necessarily 
serve as a mere store of value or a likely alternative to traditional fiat money and (ii), Ripple specializes in international transactions and has become very popular among financial institutions (see, inter alia, Ammous, 2018). That aside, there also exists a large number of technical similarities and differences across these currencies. For example, Ciaian et al. (2018) point out that Ethereum, contrary to Bitcoin, has an unlimited supply of coins; while, Ripple despite having a limited supply of coins, it makes use of a different Proof-of-Work (PoW) mechanism, compared to the other two.

It follows that, the downward trend of connectedness that is recorded in Figure 1 for the period until early 2017, is closely linked to these developments in the cryptocurrency market and their subsequent implications for investors and economic agents. In particular, we maintain that connectedness exhibits this downward trend initially, mainly due to the subdued price volatility and the corresponding low uncertainty of the period. To be more explicit, in an interesting study on forecasting the price volatility of the Bitcoin, Kristjanpoller and Minutolo (2018) report that starting in mid-2015 and until August 2017 there was an upward trend in the price of Bitcoin; however, this trend was predicated upon relatively moderate returns. Considering the omnipotence of Bitcoin in the cryptocurrency market at the time, it follows that, moderate Bitcoin returns did not inflict suspicion, upon economic agents, of speculation in the cryptocurrency market. Then apparently, this allowed economic agents and/or investors to concentrate more on the different features characterizing this ecosystem of cryptocurrencies leading to the decoupling of the relevant returns. To put differently, this relatively tranquil period for the cryptocurrency market led to the loosening of the interdependency across cryptocurrencies.

By contrast, considering the second interval that expands from early 2017 and until the end of our sample period, we note that connectedness is persistently increasing. Authors such as Bech and Garratt (2017) provide evidence that the release and the expansion of coins grew relentlessly in recent years (i.e., note that, during 2017, the market capitalization of all other currencies had equated that of Bitcoin) thus further strengthening the potential for increased connectedness across cryptocurrencies. In addition, Gandal et al. (2018) document that around mid-May 2017 the market capitalization of Bitcoin rose by 300\%, while that of other cryptocurrencies rose by even more. Subsequently, such huge increases apparently rose suspicion and uncertainty in the market. In line with our arguments presented above, we maintain that the upward trend of connectedness that is recorded for this period, stems from the high price volatility of the period (i.e., uncertainty in the cryptocurrency market driven mainly by Bitcoin). In particular, this relatively turbulent period, resulted in exacerbating fears regarding the cryptocurrency market as a whole (i.e., irrespective of the individual differences across digital currencies). The latter might also be construed as an anticipated response on behalf of economic agents given that the cryptocurrency market is new and under-researched. In their recent study Peng et al. (2018) stress the need to attain a better understanding of the potential role of cryptocurrencies in modern finance.

In order to thoroughly investigate the structural break which is evident in our connectedness results we further proceed with a disaggregated approach presented in Table 2. Given that cryptocurrency market capitalization substantially increased, starting around August 2017, we break down our period of analysis into the pre- and post-August 2017 period. We further assume that the rapid increase in the interconnectedness illustrates that the cryptocurrency market became closer connected. Furthermore, the increase in liquidity eases the trading of assets and makes this market more interesting for investors. In this regard, we assume that this jump has substantial portfolio and hedging implications and might significantly influence the dynamics within the cryptocurrency market.

Table 2 shows that interconnectedness nearly doubled. Additionally, we can see that in both periods the market is driving all cryptocurrencies since it is a net transmitter to 9 other assets. In the pre period regime we see that the Bitcoin is the most powerful transmitter followed by Litecoin and Stellar whereas all the others are receiver of shocks. This pattern changes after the break in the TCI. The post period regime indicates that Ethereum is now the strongest transmitter followed by Ripple, Bitcoin, and Bitshares. All the others are receivers of shocks. This finding is interesting since it shows that Ethereum is becoming more and more important in the cryptocurrency market whereas Bitcoin - even if still influential - is losing its leader position. ${ }^{2}$

\footnotetext{
${ }^{2}$ In an attempt to check the robustness of our main results based on the TVP-FAVAR model, we have estimated a simple TVP-VAR model consisting only of the 5 highest capitalized cryptocurrencies, namely, Bitcoin (BTC), Ethereum (ETH), Ripple (XRP), Dash (DASH), and Litecoin (LTC). These results remain qualitatively similar to our main findings, however, spillovers under this simple TVP-VAR are less pronounced, as a lot of information is lost by restricting the model to just 5 cryptocurrencies, and excluding the single cryptocurrency factor (consisting of 45 additional cryptocurrencies) that captures interdependencies in the cryptocurrency markets. The full set of results are available from the authors upon request.
} 
[Insert Table 2 around here]

In retrospect, it is quite evident from our results that periods of moderate volatility in the cryptocurrency market go along with weaker connectedness across cryptocurrency returns, while the reverse is also true. We further posit that this could be explained on the basis of the uncertainty that stems from suspicion of speculation in the particular market.

\subsection{Net Dynamic Connectedness and Market Complexity}

Turning to net transmitters and net receivers in the cryptocurrency market, we begin by presenting net connectedness results for all currencies throughout the period of analysis. These are given by Figure 2 . Note that positive values correspond to net transmitters of shocks, while negative values, to net receivers.

[Insert Figure 2 around here]

Prominent among the results illustrated in Figure 2 is the fact that Bitcoin is, for the most part, a net transmitter of shocks (i.e., to all others), while the market factor is always a net transmitter (i.e., to all others) - which can be explained by the fact that, by construction, this factor captures common movements across cryptocurrencies thus facilitating our efforts to isolate the net impact of any currency on all others. Furthermore, we note that for the most part of the period of interest, most other currencies exhibit a rather net receiving role, with short periods where some of these currencies apparently transmit (i.e., in net terms). More particularly, in the recent period that followed the unprecedented appreciation in cryptocurrencies' market capitalization, we note that Bitcoin has become a net receiver of shocks, while Ethereum (ETH) to a greater and Monero (XMR) to a lesser extent, appear to be transmitting shocks to the market. Ripple (XRP) on the other hand, is also a net recipient of shocks from other currencies. In order to put these results to a further test we also consider net pairwise connectedness. This is illustrated in Figure 3 .

\section{[Insert Figure 3 around here]}

The relevant findings are suggestive of the importance of Bitcoin (BTC). Clearly, Bitcoin is a net transmitter of shocks to all other currencies with the exception of Ethereum (ETH) which apparently transmits shocks to Bitcoin in the period towards the end of our sample. For that same interval, Ethereum also transmits shocks to Ripple (XRP), while interestingly enough, it receives from both the Monero (XMR) and the New Economy Movement (XME). On the whole, these results are suggestive of the fact that we are entering a new era in the cryptocurrency market where connectedness across cryptocurrencies gradually becomes more pronounced and at the same time, more complicated. In this regard, we strongly believe that analysis should concentrate on the individual differences that exist across the many cryptocurrencies that currently make up the market in order to better understand the corresponding manifestation of connectedness.

Within the framework of the current study which apparently suggests that (i) Bitcoin is still very influential, considering all but one relevant currencies, (ii) Ethereum affects Bitcoin returns and (iii) in turn, digital currencies such as Monero (XMR) and the New Economy Movement (XME) affect Ethereum returns, it would be rather instructive to make an initial attempt in order to identify potential factors that render these particular cryptocurrencies important for the relevant market.

Starting with Ethereum, we maintain that the apparent capacity of Ethereum to transmit shocks to the cryptocurrency market, has been supported by the recent popularity of initial coin offerings (ICOs); that is, a crowdfunding way to raise the necessary capital for new ventures. To be more explicit, according to authors such as Howell et al. (2018) the most common way for prospective venture capitalists in the cryptocurrency market to pay for the tokens they wish to purchase during an ICO is to make use of ether (i.e., Ethereums coin). Apparently, the smart-contracts technology that comes with Ethereum is crucial for the ICO process.

Turning to Monero (XMR), in an insightful study regarding crypto-mining malware attacks Zimba et al. (2018) show that in most such cases, Monero was in fact the cryptocurrency of choice. This in turn, might be very much attributed to the unique anonymity/untraceability features characterizing Monero that are thoroughly discussed in Prasad (2018). Undoubtedly, Monero could form the basis for discussions 
regarding the extent to which blockchain transactions should be transparent and traceable.

Finally, the emergence of the New Economy Movement (XME) as a key player in the cryptocurrency market can be justified by the adoption and application of a proof-of-importance protocol (POI) that improves existing protocols functions by discouraging coin-hoarding (see, Ciaian et al., 2018). It follows that, the New Economy Movement could form the basis for discussions regarding the extent to which blockchain transactions should be aiming at securing equal chances among users.

In retrospect, our results indicate that although Bitcoin remains the digital currency that exerts most of the influence in the cryptocurrency market as a whole, the unique features of the blockchain technology that comes with certain digital currencies (e.g., Ethereum, Monero, New Economy Movement) has resulted in a more complex and interrelated market. What is also evident from our analysis is that there are still open questions regarding (among others) the linkages between cryptocurrencies and (i) corporate governance (e.g., Ethereum and ICOs), (ii) transparency of transactions (e.g., Monero), and (iii), equal opportunities among cryptocurrency users (e.g., New Economy Movement). However, this is somewhat anticipated given that, with reference to the cryptocurrency market, there is definitely still much more to learn.

It follows that, increased transparency that clarifies or/and improves procedures and transactions in relation (at least) to the aforementioned issues that emerge from our study is rather imperative. Despite the fact that analyzing the legal framework in connection with transactions in the cryptocurrency market falls outside the scope of this study, it would be instructive to emphasize that increased transparency could facilitate a better understanding of the underlying differences across cryptocurrencies and subsequently (as suggested by the results of our study), this would not only widen confidence in the market, but it would also lead to new opportunities for portfolio diversification. On a parallel note, it is rather obvious that the development of the cryptocurrency market calls for the development of the appropriate legal framework as well; that is, of the necessary environment that would discourage financial crime and other illegal activities.

\subsection{A Portfolio and Risk Management Application}

To the effect that we may further support our findings that predicate upon the connectedness approach, we proceed with a simple hedging exercise. In particular, we investigate the effect of creating bivariate investment portfolios - that necessarily include either Bitcoin (i.e., the standard choice) or Ethereum (i.e., the new net transmitter that exhibits the largest market capitalization), on dynamic portfolio weights and hedge ratios.

The first step is to estimate the dynamic conditional correlations across the nine cryptocurrencies of interest. These are given in Figure 4. Notably, the dynamic conditional correlations results presented in Figure 4 are suggestive of the fact that correlation across cryptocurrencies assumes higher values from mid-2017 onwards. These findings are in line with our previous arguments that during periods of high market uncertainty connectedness across cryptocurrencies becomes more pronounced. It's also worth mentioning that the highest value corresponds to the dynamic conditional correlations between the Bitcoin and Litecoin (blue line) which, in turn, stands to reason given that both coins share similar technical characteristics (see, Ciaian et al., 2018).

\section{[Insert Figure 4 around here]}

Consecutively, making use of the corresponding conditional volatility results, we construct dynamic portfolio weights and hedge ratios in the spirit of Kroner and Ng (1998) and Kroner and Sultan (1993), respectively. These are given by Figure 5 and Figure 6 . We should also note that the results presented in this section focus on Bitcoin and Ethereum.

It would also be instructive at this point to stress once more that our analysis reveals a structural break towards the mid of 2017 (i.e., starting in August 2017 price volatility in the cryptocurrency market reached unprecedented levels). In this respect, we employ this date as a benchmark in order to draw useful conclusions regarding our portfolio exercise.

[Insert Figure 5 and Figure 6 around here]

Evident in Figure 5 is that following August 2017, dynamic portfolio weights with regard to Bitcoin are decreasing, whereas the respective weights of Ethereum are increasing, thus further highlighting the 
momentum gained by the latter in the cryptocurrency market. What is more, it is evidenced in Figure 6 that after the date that marks the structural break suggested by our study, hedge ratios in most cases persistently increase, which practically implies that including both cryptocurrencies in a portfolio could potentially result in more effective diversification outcomes. In Table 3 and 4 it is shown that the volatility within the bivariate portfolio significantly reduces in the period after August 2017 whereas before this point in time the volatility could not have been reduced using portfolio weights or hedging ratios. This supports our proposition that the increased interconnectedness - partially caused by the increased liquidity - of the cryptocurrency market is facilitating portfolio and risk management techniques.

[Insert Tables 3 and 4 around here]

Overall, it should be emphasized that this is merely an initial exercise within a relatively simplified framework; however, it is quite suggestive of the fact that we are entering a new era in the cryptocurrency market whereupon the ensuing dynamics across cryptocurrencies become more complex and deserve further investigation.

\section{Conclusions}

Investigating interrelations across different cryptocurrencies is important in order to better understand the broad spectrum of applications that comes with the newly introduced blockchain technologies and might affect, among others, monetary policy, corporate governance and risk management. Our study concentrates on risk related issues and purports to identify potential sources of influence which reside within the cryptocurrency market itself. In particular, the overriding objectives of the study are to record spillovers and to identify, net-transmitters and net-receivers among the top 9 cryptocurrencies classified by virtue of market capitalization. The period of study spans between August 7, 2015 and May 31, 2018, while the employed method is an enhanced version of the connectedness approach that was introduced by Diebold and Yllmaz (2014). In turn, identifying contagion dynamics across cryptocurrencies might very well pave the way for research that concentrates on risk hedging strategies. We maintain that understanding connectedness in the cryptocurrency market will help risk managers better appreciate the relevant risk that relates to specific cryptocurrencies, which might in turn constitute an integral part of an investment portfolio.

Results indicate that moderate price volatility in the cryptocurrency market is associated with weaker connectedness across the cryptocurrencies under investigation. At the same time, periods of high price volatility imply that the corresponding connectedness is rather strong. In fact, the period of analysis is marked by an increase in connectedness that becomes more pronounced during the interval that is characterized by high price volatility. In line with the arguments presented above, we maintain that this could be attributed to increased suspicion of speculation during the more turbulent period which is conducive to pessimistic expectations regarding the cryptocurrency market as a whole. What is also evident is that uncertainty is also intensified by the fact that the cryptocurrency market and its potential influence on the financial sector in general are still very much under-researched.

Turning to pairwise connectedness results, we note that complexity in the cryptocurrency market has markedly increased in recent years. This can be evidenced by the net transmitting role assumed by specific cryptocurrencies such as the Ethereum, the Monero and the New Economy Movement. On the other hand, Bitcoin remains the cryptocurrency that transmits most shocks to the market, while Ripple remains a key cryptocurrency given its importance for the banking sector. Specific results are suggestive of the fact that the degree of complexity in the cryptocurrency market (as captured by the connectedness approach) gradually increases given that different cryptocurrencies are endowed with different technologies and characteristics that open up a variety of different possibilities for potential users. Within the framework of our study, key issues that emerged were linked to corporate governance applications, transparency of the transactions, as well as, coin hoarding.

Furthermore, in order to put our connectedness results to the test and also to provide additional support to our arguments, we construct bivariate dynamic portfolios and hedge ratios in order to investigate whether the volatility within these portfolios declines during and after the period characterized by increased price volatility in the cryptocurrency market. Overall, results indicate that there is potential for improving hedging effectiveness in this more complex era for the cryptocurrency market. 
Potential avenues for future research in this field of study should include the thorough investigation of the specific factors that affect bivariate relationships across cryptocurrencies. In addition, research should also focus on the impact of the different functions and features that characterize each cryptocurrency on risk management. What is more, given the obvious influence of Ethereum on Bitcoin and/or the apparent rapid growth of market capitalization of the cryptocurrencies that followed Bitcoin, it would also be interesting to investigate whether other cryptocurrencies have similar (i.e., to Bitcoin) diversification effects on investment portfolios. On the whole, we strongly believe that this is a promising field of study with a multitude of applications that influence contemporary finance and that there is still plenty of room for further research.

\section{Acknowledgements}

We would like to thank the editor (Jonathan A. Batten) and two anonymous reviewers for their very insightful comments and suggestions on a previous version of this paper. In addition, part of this study was completed in academic year 2017-18; that is, during the employment of Ioannis Chatziantoniou at Webster Vienna Private University. The usual disclaimer applies.

\section{References}

Al-Yahyaee, K. H., Mensi, W., and Yoon, S.-M. (2018). Efficiency, multifractality, and the long-memory property of the bitcoin market: A comparative analysis with stock, currency, and gold markets. Finance Research Letters.

Ammous, S. (2018). Can cryptocurrencies fulfil the functions of money? The Quarterly Review of Economics and Finance.

Anscombe, F. J. and Glynn, W. J. (1983). Distribution of the kurtosis statistic b 2 for normal samples. Biometrika, 70(1):227-234.

Antonakakis, N., Chatziantoniou, I., and Gabauer, D. (2018a). European currency co-movements and contagion: Evidence from a bayesian tvp-(pseudo) favar model. Working Paper 3167203, SSRN.

Antonakakis, N., Cunado, J., Filis, G., Gabauer, D., and De Gracia, F. P. (2018b). Oil and asset classes implied volatilities: Dynamic connectedness and investment strategies.

Antonakakis, N. and Gabauer, D. (2017). Refined measures of dynamic connectedness based on TVPVAR. MPRA Paper 78282, University Library of Munich, Germany.

Bariviera, A. F. (2017). The inefficiency of bitcoin revisited: A dynamic approach. Economics Letters, 161:1-4.

Baur, D. G., Dimpfl, T., and Kuck, K. (2018a). Bitcoin, gold and the us dollar-a replication and extension. Finance Research Letters, 25:103-110.

Baur, D. G., Hong, K., and Lee, A. D. (2018b). Bitcoin: Medium of exchange or speculative assets? Journal of International Financial Markets, Institutions and Money.

Bech, M. L. and Garratt, R. (2017). Central bank cryptocurrencies. BIS Quarterly Review.

Berentsen, A., Schar, F., et al. (2018). A short introduction to the world of cryptocurrencies. Federal Reserve Bank of St. Louis Review, 100(1):1-16.

Bernanke, B. S., Boivin, J., and Eliasz, P. (2005). Measuring the effects of monetary policy: a factoraugmented vector autoregressive (favar) approach. The Quarterly journal of economics, 120(1):387-422.

Blau, B. M. (2018). Price dynamics and speculative trading in bitcoin. Research in International Business and Finance, 43:15-21.

Bordo, M. D. and Levin, A. T. (2017). Central bank digital currency and the future of monetary policy. Economics Working Papers 17104, Hoover Institution, Stanford University.

Bouri, E., Gupta, R., Tiwari, A. K., and Roubaud, D. (2017a). Does bitcoin hedge global uncertainty? evidence from wavelet-based quantile-in-quantile regressions. Finance Research Letters, 23:87-95. 
Bouri, E., Molnár, P., Azzi, G., Roubaud, D., and Hagfors, L. I. (2017b). On the hedge and safe haven properties of bitcoin: Is it really more than a diversifier? Finance Research Letters, 20:192-198.

Brauneis, A. and Mestel, R. (2018). Price discovery of cryptocurrencies: Bitcoin and beyond. Economics Letters, 165:58-61.

Caporale, G. M., Gil-Alana, L., and Plastun, A. (2018). Persistence in the cryptocurrency market. Research in International Business and Finance.

Chan, W. H., Le, M., and Wu, Y. W. (2018). Holding bitcoin longer: The dynamic hedging abilities of bitcoin. The Quarterly Review of Economics and Finance.

Cheah, E.-T. and Fry, J. (2015). Speculative bubbles in bitcoin markets? an empirical investigation into the fundamental value of bitcoin. Economics Letters, 130:32-36.

Cheah, E.-T., Mishra, T., Parhi, M., and Zhang, Z. (2018). Long memory interdependency and inefficiency in bitcoin markets. Economics Letters, 167:18-25.

Ciaian, P., Rajcaniova, M., et al. (2018). Virtual relationships: Short-and long-run evidence from bitcoin and altcoin markets. Journal of International Financial Markets, Institutions and Money, 52:173-195.

Corbet, S., Larkin, C. J., Lucey, B. M., Meegan, A., and Yarovaya, L. (2018a). The volatility generating effects of macroeconomic news on cryptocurrency returns.

Corbet, S., Lucey, B. M., Urquhart, A., and Yarovaya, L. (2018b). Cryptocurrencies as a financial asset: A systematic analysis.

Corbet, S., Lucey, B. M., and Yarovaya, L. (2017). Datestamping the bitcoin and ethereum bubbles. Finance Research Letters.

Corbet, S., Meegan, A., Larkin, C., Lucey, B. M., and Yarovaya, L. (2018c). Exploring the dynamic relationships between cryptocurrencies and other financial assets. Economics Letters, 165:28-34.

D'Agostino, R. B. (1970). Transformation to normality of the null distribution of g1. Biometrika, pages $679-681$.

Diebold, F. X. and Yllmaz, K. (2014). On the network topology of variance decompositions: Measuring the connectedness of financial firms. Journal of Econometrics, 182(1):119-134.

Dwyer, G. P. (2015). The economics of bitcoin and similar private digital currencies. Journal of Financial Stability, 17:81-91.

Dyhrberg, A. H. (2016). Hedging capabilities of bitcoin. is it the virtual gold? Finance Research Letters, 16:139-144.

Ederington, L. H. (1979). The hedging performance of the new futures markets. The Journal of Finance, 34(1):157-170.

Engle, R. (2002). Dynamic conditional correlation. Journal of Business \& Economic Statistics, 20(3):339350 .

Fernández-Villaverde, J. and Sanches, D. (2016). Can currency competition work? Working Paper 22157, National Bureau of Economic Research.

Fisher, T. J. and Gallagher, C. M. (2012). New weighted portmanteau statistics for time series goodness of fit testing. Journal of the American Statistical Association, 107(498):777-787.

Fry, J. and Cheah, E.-T. (2016). Negative bubbles and shocks in cryptocurrency markets. International Review of Financial Analysis, 47:343-352.

Gandal, N., Hamrick, J., Moore, T., and Oberman, T. (2018). Price manipulation in the bitcoin ecosystem. Journal of Monetary Economics, 95:86-96.

Gkillas, K. and Katsiampa, P. (2018). An application of extreme value theory to cryptocurrencies. Economics Letters, 164:109-111.

Guesmi, K., Saadi, S., Abid, I., and Ftiti, Z. (2018). Portfolio diversification with virtual currency: Evidence from bitcoin. International Review of Financial Analysis.

Hentschel, L. (1995). All in the family nesting symmetric and asymmetric garch models. Journal of Financial Economics, 39(1):71-104. 
Howell, S. T., Niessner, M., and Yermack, D. (2018). Initial coin offerings: Financing growth with cryptocurrency token sales. Working Paper 24774, National Bureau of Economic Research.

Jarque, C. M. and Bera, A. K. (1980). Efficient tests for normality, homoscedasticity and serial independence of regression residuals. Economics letters, 6(3):255-259.

Jiang, Y., Nie, H., and Ruan, W. (2018). Time-varying long-term memory in bitcoin market. Finance Research Letters, 25:280-284.

Katsiampa, P. (2017). Volatility estimation for bitcoin: A comparison of garch models. Economics Letters, 158:3-6.

Koop, G. and Korobilis, D. (2014). A new index of financial conditions. European Economic Review, 71:101-116.

Koop, G., Pesaran, M. H., and Potter, S. M. (1996). Impulse Response Analysis in Nonlinear Multivariate Models. Journal of Econometrics, 74(1):119-147.

Kristjanpoller, W. and Minutolo, M. C. (2018). A hybrid volatility forecasting framework integrating garch, artificial neural network, technical analysis and principal components analysis. Expert Systems with Applications, 109:1-11.

Kristoufek, L. (2018). On bitcoin markets (in) efficiency and its evolution. Physica A: Statistical Mechanics and its Applications, 503:257-262.

Kroner, K. F. and Ng, V. K. (1998). Modeling asymmetric comovements of asset returns. Review of Financial Studies, 11(4):817-844.

Kroner, K. F. and Sultan, J. (1993). Time-varying distributions and dynamic hedging with foreign currency futures. Journal of Financial and Quantitative Analysis, 28(4):535-551.

Li, X. and Wang, C. A. (2017). The technology and economic determinants of cryptocurrency exchange rates: The case of bitcoin. Decision Support Systems, 95:49-60.

Nadarajah, S. and Chu, J. (2017). On the inefficiency of bitcoin. Economics Letters, 150:6-9.

Patton, A. J. (2006). Modelling asymmetric exchange rate dependence. International Economic Review, $47(2): 527-556$.

Peng, Y., Albuquerque, P. H. M., de Sá, J. M. C., Padula, A. J. A., and Montenegro, M. R. (2018). The best of two worlds: Forecasting high frequency volatility for cryptocurrencies and traditional currencies with support vector regression. Expert Systems with Applications, 97:177-192.

Pesaran, H. H. and Shin, Y. (1998). Generalized impulse response analysis in linear multivariate models. Economics Letters, 58(1):17-29.

Phillip, A., Chan, J., and Peiris, S. (2018). A new look at cryptocurrencies. Economics Letters, 163:6-9.

Prasad, E. (2018). Central banking in a digital age: Stock-taking and preliminary thoughts. Brookings Institution.

Schilling, L. and Uhlig, H. (2018). Some simple bitcoin economics. Working Paper 24483, National Bureau of Economic Research.

Selmi, R., Mensi, W., Hammoudeh, S., and Bouoiyour, J. (2018). Is bitcoin a hedge, a safe haven or a diversifier for oil price movements? a comparison with gold. Energy Economics.

Sensoy, A. (2018). The inefficiency of bitcoin revisited: A high-frequency analysis with alternative currencies. Finance Research Letters.

Sklar, M. (1959). Fonctions de repartition an dimensions et leurs marges. Publ. Inst. Statist. Univ. Paris, 8:229-231.

Stock, J., Elliott, G., and Rothenberg, T. (1996). Efficient tests for an autoregressive unit root. Econometrica, 64(4):813-836.

Symitsi, E. and Chalvatzis, K. J. (2018). Return, volatility and shock spillovers of bitcoin with energy and technology companies. Economics Letters, 170:127-130. 
Tiwari, A. K., Jana, R., Das, D., and Roubaud, D. (2018). Informational efficiency of bitcoinan extension. Economics Letters, 163:106-109.

Urquhart, A. (2016). The inefficiency of bitcoin. Economics Letters, 148:80-82.

Urquhart, A. and Zhang, H. (2018). Is bitcoin a hedge or safe-haven for currencies? An intraday analysis. Working Paper 3114108, SSRN.

Wei, W. C. (2018). Liquidity and market efficiency in cryptocurrencies. Economics Letters, 168:21-24.

Williamson, S. et al. (2018). Is bitcoin a waste of resources? Federal Reserve Bank of St. Louis Review, 100(2):107-15.

Yermack, D. (2017). Corporate governance and blockchains. Review of Finance, 21(1):7-31.

Yermack, D. (2018). The potential of digital currency and blockchains. NBER Reporter, (1):14-17.

Zimba, A., Wang, Z., Mulenga, M., and Odongo, N. H. (2018). Crypto mining attacks in information systems: An emerging threat to cyber security. Journal of Computer Information Systems, pages 1-12. 
Figure 1: Dynamic Total Connectedness

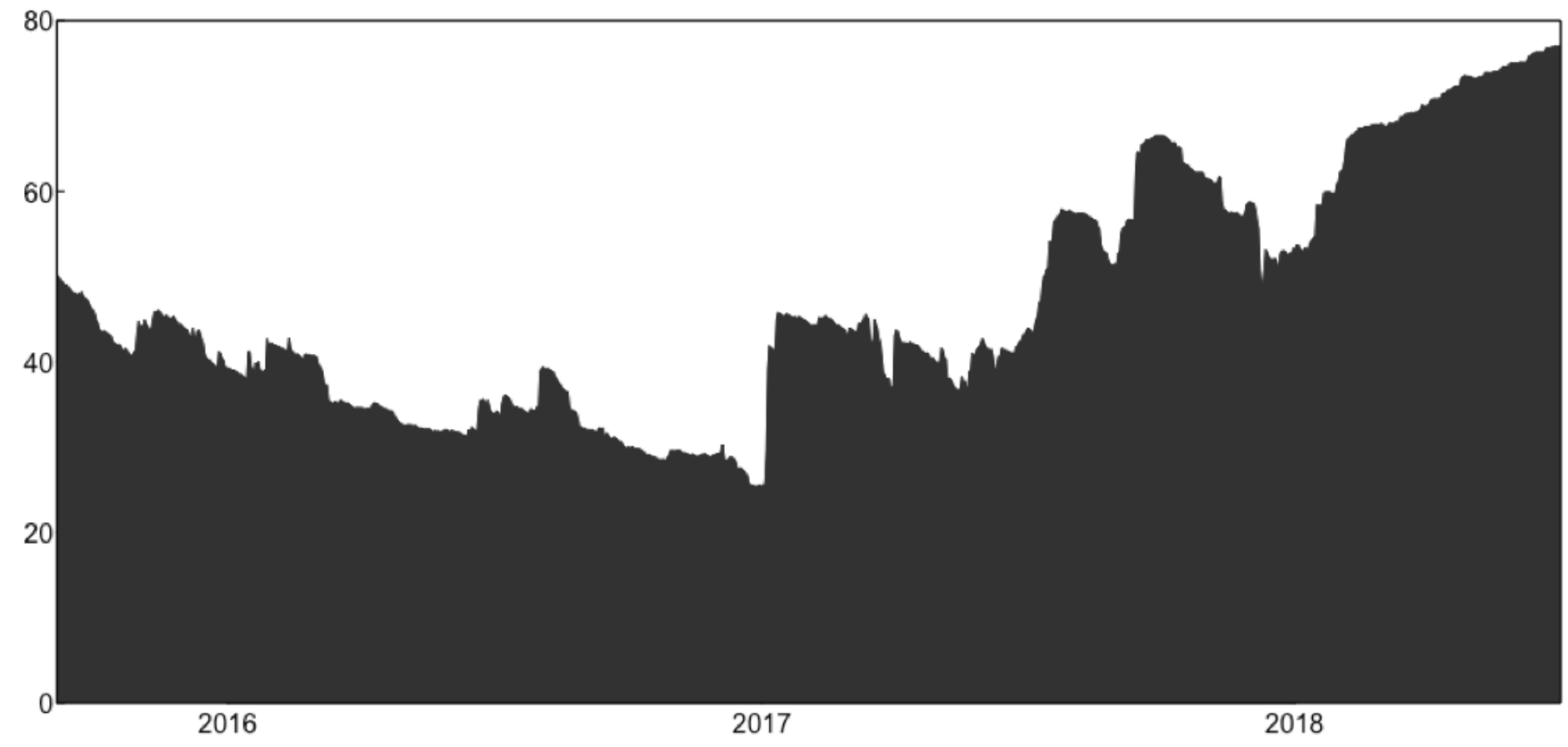

Figure 2: Net Directional Connectedness
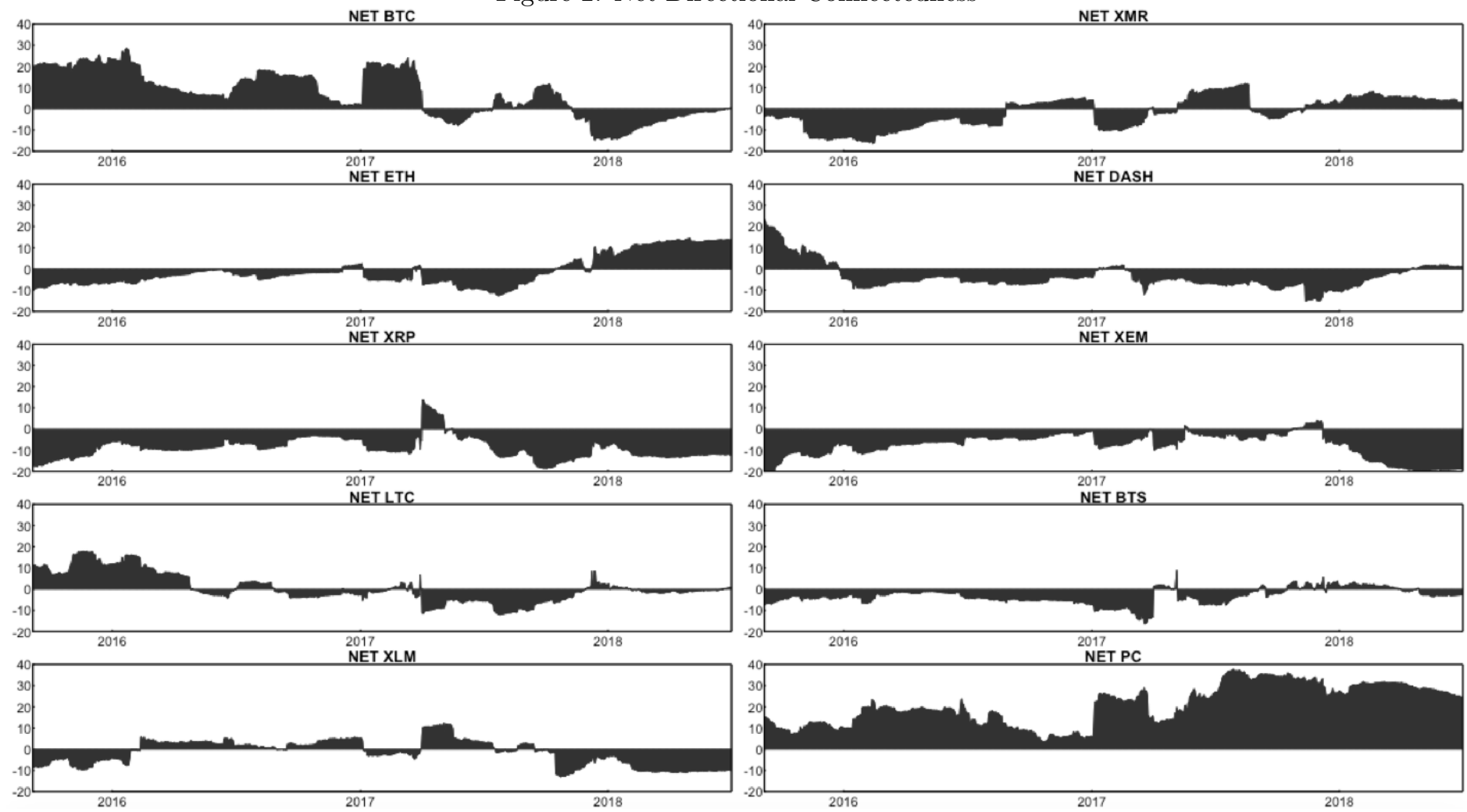
Figure 3: Net Pairwise Directional Connectedness
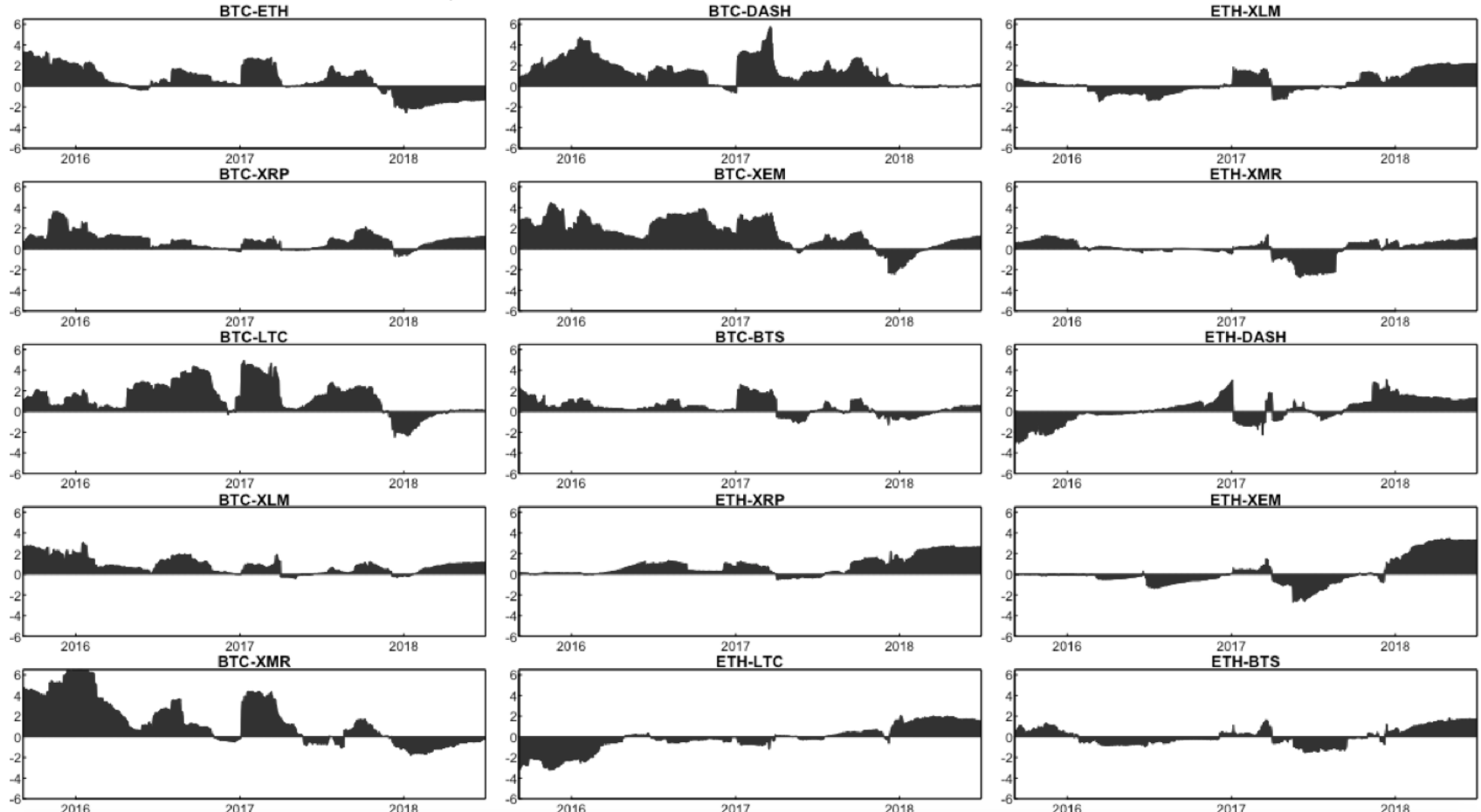

Figure 4: Dynamic Conditional Correlations

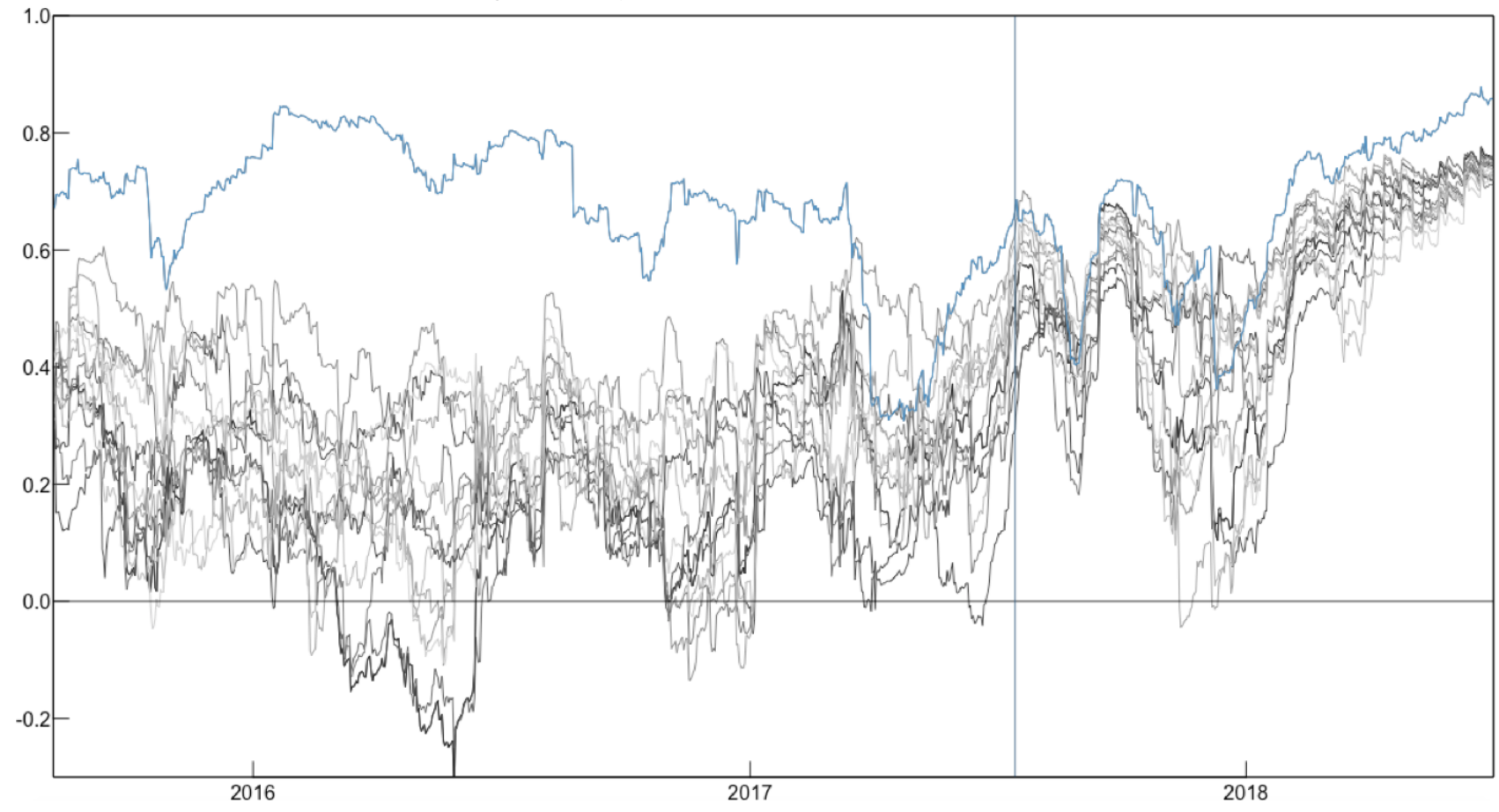


Figure 5: Dynamic Portfolio Weights

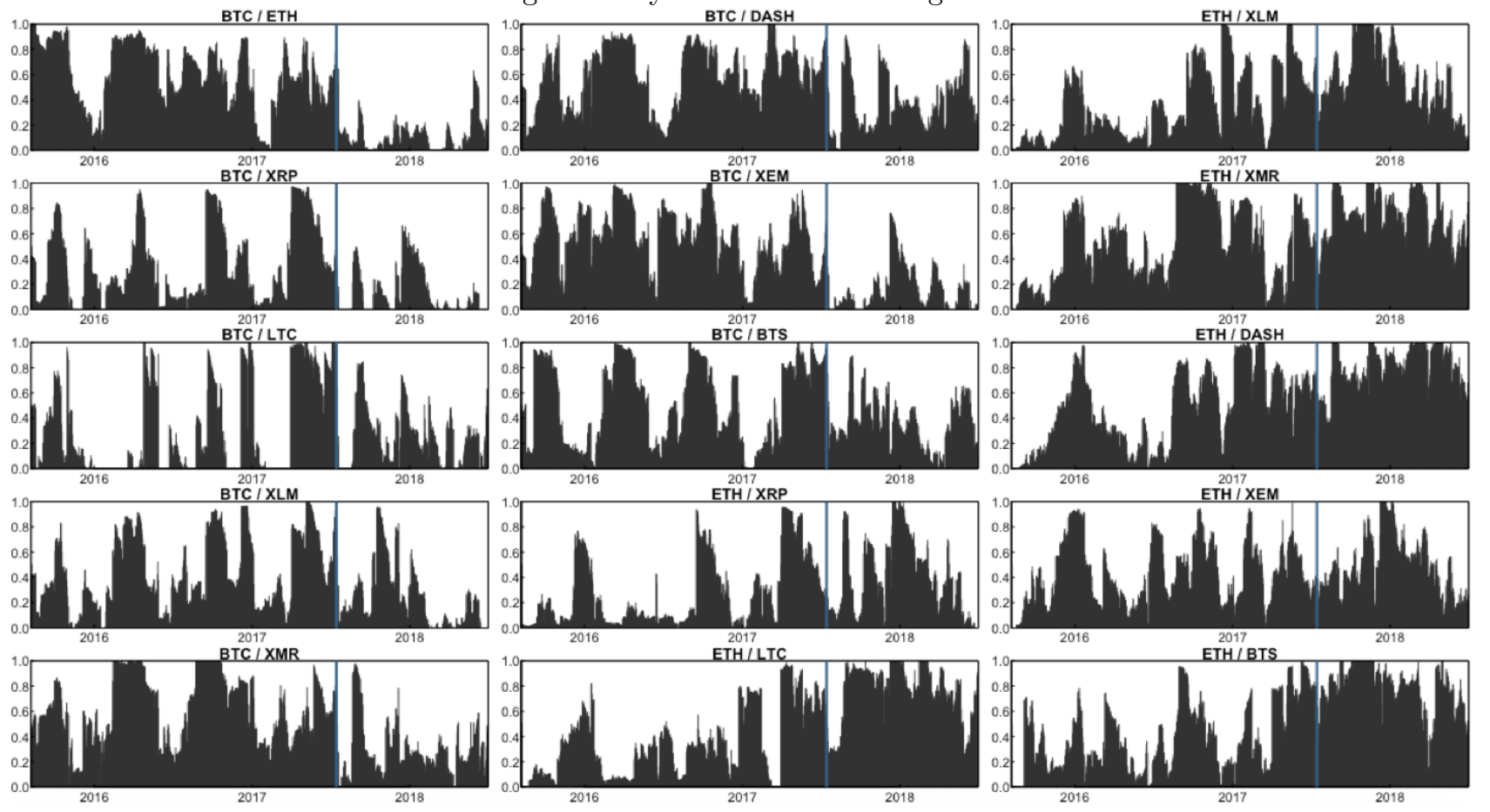

Figure 6: Dynamic Hedge Ratios
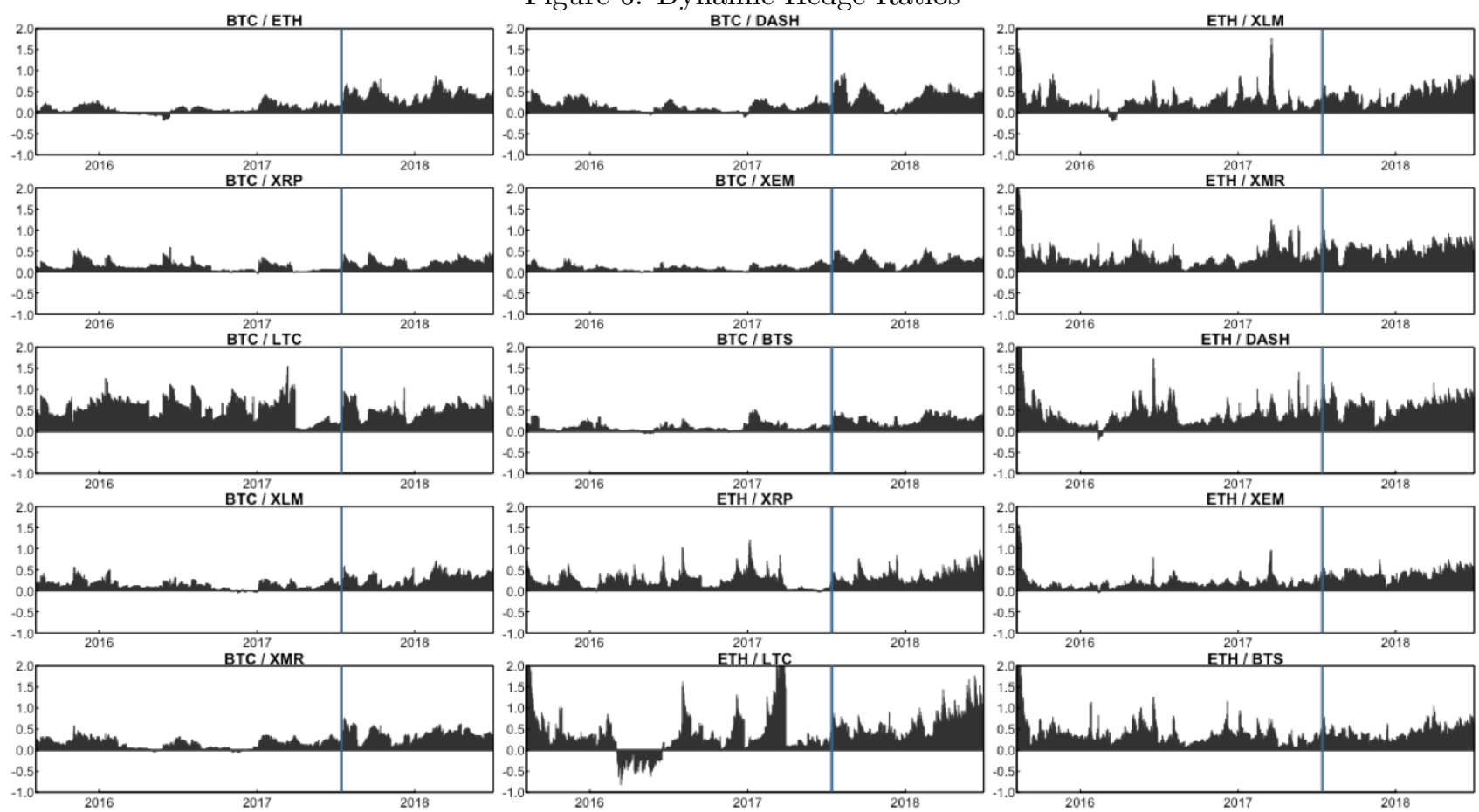
Table 1: Summary Statistics: Crypotcurrency Returns

\begin{tabular}{|c|c|c|c|c|c|c|c|c|c|c|}
\hline & BTC & ETH & $\mathrm{XRP}$ & LTC & XLM & XMR & DASH & XEM & BTS & $\mathrm{PC}$ \\
\hline Mean & 0.358 & 0.755 & 0.723 & 0.411 & 0.834 & 0.748 & 0.579 & 1.113 & 0.695 & 0.000 \\
\hline Variance & 16.642 & 58.226 & 89.45 & 39.079 & 99.823 & 60.491 & 39.393 & 118.865 & 78.303 & 0.182 \\
\hline Skewness & $\begin{array}{c}0.151 * * \\
(0.045)\end{array}$ & $\begin{array}{c}0.179 * * \\
(0.018)\end{array}$ & $\begin{array}{c}7.979 * * * \\
(0.000)\end{array}$ & $\begin{array}{c}2.637 * * * \\
(0.000)\end{array}$ & $\begin{array}{c}4.015 * * * \\
(0.000)\end{array}$ & $\begin{array}{c}2.119 * * * \\
(0.000)\end{array}$ & $\begin{array}{c}1.701 * * * \\
(0.000)\end{array}$ & $\begin{array}{c}4.953 * * * \\
(0.000)\end{array}$ & $\begin{array}{c}1.948 * * * \\
(0.000)\end{array}$ & $\begin{array}{c}-0.350 * * * \\
(0.000)\end{array}$ \\
\hline Kurtosis & $\begin{array}{c}5.231 * * * \\
(0.000)\end{array}$ & $\begin{array}{c}13.034 * * * \\
(0.000)\end{array}$ & $\begin{array}{c}128.209 * * * \\
(0.000)\end{array}$ & $\begin{array}{c}21.806 * * * \\
(0.000)\end{array}$ & $\begin{array}{c}32.925 * * * \\
(0.000)\end{array}$ & $\begin{array}{c}15.676 * * * \\
(0.000)\end{array}$ & $\begin{array}{c}10.214 * * * \\
(0.000)\end{array}$ & $\begin{array}{c}62.483 * * * \\
(0.000)\end{array}$ & $\begin{array}{c}11.299 * * * \\
(0.000)\end{array}$ & $\begin{array}{c}4.167 * * * \\
(0.000)\end{array}$ \\
\hline JB & $\begin{array}{c}1213.8 * * * \\
(0.000)\end{array}$ & $\begin{array}{c}7515.5 * * * \\
(0.000)\end{array}$ & $\begin{array}{c}737928.1 * * * \\
(0.000)\end{array}$ & $\begin{array}{c}22251.3 * * * \\
(0.000)\end{array}$ & $\begin{array}{c}50775.7 * * * \\
(0.000)\end{array}$ & $\begin{array}{c}11656.8 * * * \\
(0.000)\end{array}$ & $\begin{array}{c}5123.2 * * * \\
(0.000)\end{array}$ & $\begin{array}{c}176930.7 * * * \\
(0.000)\end{array}$ & $\begin{array}{c}6315.4 * * * \\
(0.000)\end{array}$ & $\begin{array}{c}789.2 * * * \\
(0.000)\end{array}$ \\
\hline ERS & $\begin{array}{c}-13.986 * * * \\
(0.000)\end{array}$ & $\begin{array}{c}-11.806 * * * \\
(0.000)\end{array}$ & $\begin{array}{c}-12.346 * * * \\
(0.000)\end{array}$ & $\begin{array}{c}-8.719 * * * \\
(0.000)\end{array}$ & $\begin{array}{c}-9.470 * * * \\
(0.000)\end{array}$ & $\begin{array}{c}-12.435 * * * \\
(0.000)\end{array}$ & $\begin{array}{c}-4.350 * * * \\
(0.000)\end{array}$ & $\begin{array}{c}-12.400 * * * \\
(0.000)\end{array}$ & $\begin{array}{c}-10.963 * * * \\
(0.000)\end{array}$ & $\begin{array}{c}-7.844 * * * \\
(0.000)\end{array}$ \\
\hline$Q(20)$ & $\begin{array}{c}18.446 * * \\
(0.037)\end{array}$ & $\begin{array}{c}25.140 * * * \\
(0.002)\end{array}$ & $\begin{array}{c}56.507 * * * \\
(0.000)\end{array}$ & $\begin{array}{c}26.435 * * * \\
(0.001)\end{array}$ & $\begin{array}{c}48.426 * * * \\
(0.000)\end{array}$ & $\begin{array}{c}34.822 * * * \\
(0.000)\end{array}$ & $\begin{array}{c}17.969 * * \\
(0.040)\end{array}$ & $\begin{array}{c}26.460 * * * \\
(0.001)\end{array}$ & $\begin{array}{c}26.714 * * * \\
(0.001)\end{array}$ & $\begin{array}{c}29.949 * * * \\
(0.000)\end{array}$ \\
\hline$Q^{2}(20)$ & $\begin{array}{c}129.645 * * * \\
(0.000)\end{array}$ & $\begin{array}{c}182.923 * * * \\
(0.000)\end{array}$ & $\begin{array}{c}22.825 * * * \\
(0.005)\end{array}$ & $\begin{array}{c}56.040 * * * \\
(0.000)\end{array}$ & $\begin{array}{c}220.033 * * * \\
(0.000)\end{array}$ & $\begin{array}{c}98.816 * * * \\
(0.000)\end{array}$ & $\begin{array}{c}30.456 * * * \\
(0.000)\end{array}$ & $\begin{array}{c}3.650 \\
(0.991)\end{array}$ & $\begin{array}{c}79.697 * * * \\
(0.000)\end{array}$ & $\begin{array}{c}239.424 * * * \\
(0.000)\end{array}$ \\
\hline \multirow[t]{3}{*}{$A R C H(20)$} & $\begin{array}{c}32.305 * * * \\
(0.000)\end{array}$ & $\begin{array}{c}170.269 * * * \\
(0.000)\end{array}$ & $\begin{array}{c}17.254 * \\
(0.052)\end{array}$ & $\begin{array}{c}32.917 * * * \\
(0.000)\end{array}$ & $\begin{array}{c}5.516 \\
(0.929) \\
\end{array}$ & $\begin{array}{c}94.971 * * * \\
(0.000)\end{array}$ & $\begin{array}{c}21.879 * * * \\
(0.007)\end{array}$ & $\begin{array}{c}1.093 \\
(1.000)\end{array}$ & $\begin{array}{l}12.784 \\
(0.244)\end{array}$ & $\begin{array}{c}73.763 * * * \\
(0.000)\end{array}$ \\
\hline & \multicolumn{10}{|c|}{ Unconditional Correlation } \\
\hline & BTC & ETH & $\mathrm{XRP}$ & LTC & XLM & XMR & DASH & XEM & BTS & $\mathrm{PC}$ \\
\hline BTC & 1.000 & 0.329 & 0.211 & 0.534 & 0.282 & 0.413 & 0.409 & 0.299 & 0.353 & 0.691 \\
\hline ETH & 0.329 & 1.000 & 0.144 & 0.303 & 0.187 & 0.299 & 0.316 & 0.203 & 0.332 & 0.416 \\
\hline $\mathrm{XRP}$ & 0.211 & 0.144 & 1.000 & 0.277 & 0.485 & 0.185 & 0.129 & 0.199 & 0.406 & 0.366 \\
\hline LTC & 0.534 & 0.303 & 0.277 & 1.000 & 0.296 & 0.340 & 0.358 & 0.320 & 0.338 & 0.564 \\
\hline XLM & 0.282 & 0.187 & 0.485 & 0.296 & 1.000 & 0.293 & 0.206 & 0.310 & 0.457 & 0.463 \\
\hline XMR & 0.413 & 0.299 & 0.185 & 0.340 & 0.293 & 1.000 & 0.405 & 0.214 & 0.283 & 0.494 \\
\hline DASH & 0.409 & 0.316 & 0.129 & 0.358 & 0.206 & 0.405 & 1.000 & 0.254 & 0.300 & 0.480 \\
\hline XEM & 0.299 & 0.203 & 0.199 & 0.320 & 0.310 & 0.214 & 0.254 & 1.000 & 0.285 & 0.426 \\
\hline BTS & 0.353 & 0.332 & 0.406 & 0.338 & 0.457 & 0.283 & 0.300 & 0.285 & 1.000 & 0.582 \\
\hline $\mathrm{PC}$ & 0.691 & 0.416 & 0.366 & 0.564 & 0.463 & 0.494 & 0.480 & 0.426 & 0.582 & 1.000 \\
\hline
\end{tabular}

Notes: $* * * * *, *$ denote significance at $1 \%, 5 \%$ and $10 \%$ significance level; Skewness: D'Agostino (1970) test;

Kurtosis: Anscombe and Glynn (1983) test; JB: Jarque and Bera (1980) normality test; ERS: Stock et al. (1996) unit-root test; LB(20) and LiMak(20): Fisher and Gallagher (2012) weighted portmanteau test.

Table 2: Dynamic Connectedness Table

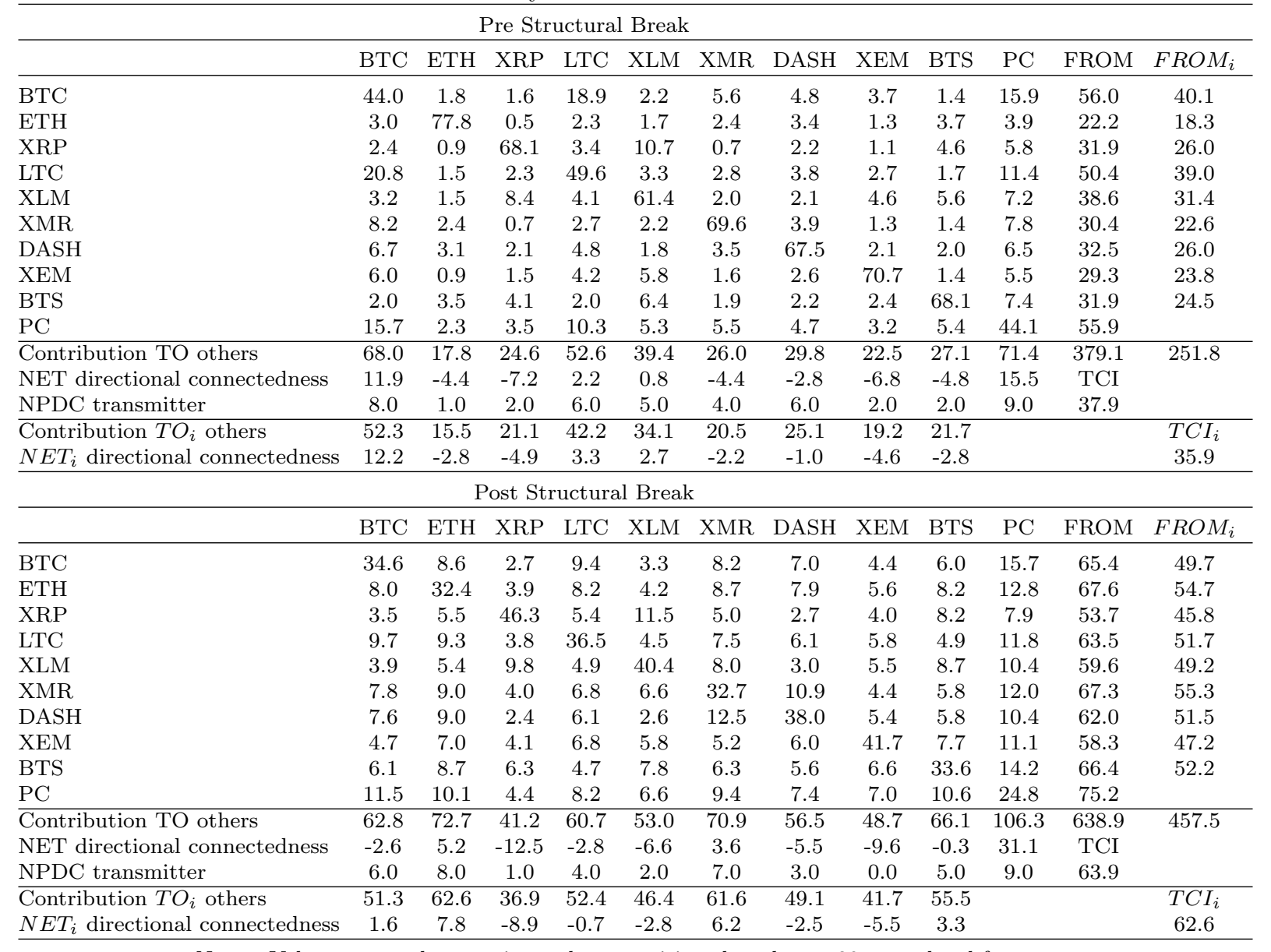

Notes: Values reported are variance decompositions based on a 20-step-ahead forecasts. In both periods, a TVP-VAR lag length of order 1 is selected by the BIC. 
Table 3: Dynamic Portfolio Weights and Hedging Effectiveness

\begin{tabular}{|c|c|c|c|c|c|c|c|c|c|c|c|c|c|c|c|c|}
\hline \multirow[b]{2}{*}{$w_{i j}$} & \multicolumn{8}{|c|}{ Pre Structural Break } & \multicolumn{8}{|c|}{ Post Structural Break } \\
\hline & Median & Std.Dev. & $5 \%$ & $95 \%$ & $H E_{j}$ & p-value & $H E_{i}$ & p-value & Median & Std.Dev. & $5 \%$ & $95 \%$ & $H E_{j}$ & p-value & $H E_{i}$ & p-value \\
\hline BTC ETH & 0.93 & 0.13 & 0.60 & 1.00 & 1.02 & 0.83 & $0.15 * * *$ & 0.00 & 0.71 & 0.26 & 0.29 & 1.00 & $0.53 * * *$ & 0.00 & $0.69 * *$ & 0.02 \\
\hline BTC XRP & 0.93 & 0.22 & 0.35 & 1.00 & 0.99 & 0.98 & $0.11 * * *$ & 0.00 & 1.00 & 0.14 & 0.66 & 1.00 & $0.88 *$ & 0.09 & $0.39 * * *$ & 0.00 \\
\hline BTC LTC & 0.91 & 0.32 & 0.01 & 1.00 & $0.83 * *$ & 0.04 & $0.55 * * *$ & 0.00 & 0.97 & 0.26 & 0.18 & 1.00 & $0.62 * * *$ & 0.00 & $0.53 * * *$ & 0.00 \\
\hline BTC XLM & 0.93 & 0.16 & 0.48 & 1.00 & 1.09 & 0.92 & $0.11 * * *$ & 0.00 & 0.96 & 0.16 & 0.52 & 1.00 & $0.91 *$ & 0.09 & $0.27 * * *$ & 0.00 \\
\hline BTC XMR & 0.98 & 0.10 & 0.67 & 1.00 & 0.93 & 0.28 & $0.17 * * *$ & 0.00 & 0.92 & 0.19 & 0.45 & 1.00 & $0.69 * * *$ & 0.00 & 0.47 & 0.00 \\
\hline BTC DASH & 0.89 & 0.16 & 0.46 & 1.00 & 0.91 & 0.51 & $0.29 * * *$ & 0.00 & 0.80 & 0.26 & 0.26 & 1.00 & $0.66 * * *$ & 0.00 & $0.54 * * *$ & 0.00 \\
\hline BTC BTS & 0.92 & 0.17 & 0.50 & 1.00 & 0.96 & 0.86 & $0.13 * * *$ & 0.00 & 0.97 & 0.13 & 0.68 & 1.00 & $0.72 * * *$ & 0.00 & $0.31 * * *$ & 0.00 \\
\hline$\overline{\text { ETH XRP }}$ & 0.35 & 0.28 & 0.06 & 0.96 & 1.03 & 0.86 & $0.29 *$ & 0.07 & 0.98 & 0.20 & 0.42 & 1.00 & $0.79 * * *$ & 0.01 & $0.54 * *$ & 0.04 \\
\hline ETH LTC & 0.18 & 0.28 & 0.00 & 0.93 & 1.02 & 0.97 & 0.81 & 0.24 & 0.49 & 0.35 & 0.00 & 1.00 & $0.50 * * *$ & 0.00 & $0.61 *$ & 0.07 \\
\hline ETH XLM & 0.45 & 0.26 & 0.05 & 0.95 & 1.04 & 0.93 & $0.37 * * *$ & 0.00 & 0.76 & 0.23 & 0.28 & 1.00 & $0.85 * *$ & 0.04 & $0.31 * * *$ & 0.00 \\
\hline ETH XMR & 0.52 & 0.26 & 0.07 & 0.93 & 1.01 & 0.69 & $0.60 * * *$ & 0.00 & 0.69 & 0.23 & 0.25 & 1.00 & $0.65 * * *$ & 0.00 & $0.59 * * *$ & 0.00 \\
\hline ETH DASH & 0.34 & 0.24 & 0.01 & 0.81 & 1.00 & 0.80 & $0.79 * *$ & 0.03 & 0.50 & 0.26 & 0.08 & 0.97 & $0.66 * * *$ & 0.00 & 0.75 & 0.30 \\
\hline ETH XEM & 0.69 & 0.22 & 0.24 & 0.95 & 1.12 & 0.66 & $0.43 * * *$ & 0.00 & 0.89 & 0.15 & 0.55 & 1.00 & $0.94 *$ & 0.09 & $0.25 * * *$ & 0.00 \\
\hline ETH BTS & 0.45 & 0.27 & 0.05 & 0.98 & 0.93 & 0.61 & $0.53 * * *$ & 0.00 & 0.90 & 0.20 & 0.40 & 1.00 & $0.65 * * *$ & 0.00 & $0.43 * * *$ & 0.00 \\
\hline
\end{tabular}

Notes: $* * *, * *, *$ denote significance at $1 \%, 5 \%$ and $10 \%$ significance level.

Table 4: Dynamic Hedge Ratios and Hedging Effectiveness

\begin{tabular}{|c|c|c|c|c|c|c|c|c|c|c|c|c|}
\hline \multirow[b]{2}{*}{$\underline{\beta_{i j}}$} & \multicolumn{6}{|c|}{ Pre Structural Break } & \multicolumn{6}{|c|}{ Post Structural Break } \\
\hline & Median & Std.Dev. & $5 \%$ & $95 \%$ & $\mathrm{HE}$ & p-value & Median & Std.Dev. & $5 \%$ & $95 \%$ & $\mathrm{HE}$ & p-value \\
\hline ВTC ЕTH & 0.41 & 0.69 & -0.75 & 1.27 & 1.02 & 0.83 & 0.64 & 0.44 & 0.20 & 1.57 & $0.53 * * *$ & 0.00 \\
\hline BTC XRP & 0.58 & 0.41 & 0.08 & 1.31 & 0.99 & 0.98 & 0.98 & 0.52 & 0.21 & 1.91 & 0.88 & 0.14 \\
\hline BTC LTC & 0.94 & 0.46 & 0.51 & 1.97 & $0.83 *$ & 0.06 & 0.97 & 0.26 & 0.48 & 1.36 & $0.62 * * *$ & 0.00 \\
\hline BTC XLM & 0.63 & 0.72 & -0.05 & 1.79 & 1.09 & 0.92 & 0.90 & 0.50 & 0.34 & 1.87 & $0.91 *$ & 0.09 \\
\hline BTC XMR & 0.91 & 1.10 & -0.16 & 2.51 & 0.93 & 0.28 & 0.86 & 0.45 & 0.28 & 1.65 & $0.69 * * *$ & 0.00 \\
\hline BTC DASH & 0.54 & 0.38 & -0.01 & 1.12 & 0.91 & 0.51 & 0.70 & 0.45 & 0.03 & 1.41 & $0.66 * * *$ & 0.00 \\
\hline BTC XEM & 1.02 & 0.62 & 0.19 & 2.30 & 0.92 & 0.69 & 0.90 & 0.50 & 0.21 & 1.90 & $0.85 *$ & 0.09 \\
\hline BTC BTS & 0.54 & 0.66 & -0.05 & 2.02 & 0.96 & 0.86 & 0.92 & 0.45 & 0.31 & 1.75 & $0.72 * * *$ & 0.00 \\
\hline$\overline{\mathrm{ETH}} \mathrm{BTC}$ & 0.07 & 0.10 & -0.04 & 0.26 & 1.03 & 0.86 & 0.40 & 0.15 & 0.18 & 0.70 & $0.79 * * *$ & 0.01 \\
\hline ETH XRP & 0.12 & 0.13 & 0.03 & 0.40 & 1.02 & 0.97 & 0.94 & 0.28 & 0.49 & 1.41 & $0.50 * * *$ & 0.00 \\
\hline ETH LTC & 0.10 & 0.24 & -0.07 & 0.65 & 1.04 & 0.93 & 0.63 & 0.30 & 0.36 & 1.30 & $0.85 * *$ & 0.04 \\
\hline ETH XLM & 0.21 & 0.35 & 0.02 & 0.77 & 1.01 & 0.69 & 0.73 & 0.50 & 0.49 & 1.81 & $0.65 * * *$ & 0.00 \\
\hline ETH XMR & 0.34 & 0.25 & 0.10 & 0.76 & 1.00 & 0.80 & 0.73 & 0.33 & 0.49 & 1.30 & $0.66 * * *$ & 0.00 \\
\hline ETH DASH & 0.19 & 0.18 & 0.06 & 0.62 & 1.12 & 0.66 & 0.64 & 0.19 & 0.38 & 0.94 & 0.94 & 0.14 \\
\hline ETH XEM & 0.29 & 0.19 & 0.06 & 0.64 & 0.93 & 0.61 & 0.85 & 0.53 & 0.56 & 1.26 & $0.65 * * *$ & 0.00 \\
\hline ETH BTS & 0.29 & 0.25 & 0.12 & 0.84 & 0.92 & 0.43 & 0.85 & 0.26 & 0.52 & 1.40 & $0.44 * * *$ & 0.00 \\
\hline$\overline{\mathrm{XRP} B T C}$ & 0.10 & 0.11 & 0.00 & 0.36 & 0.80 & 0.35 & 0.23 & 0.10 & 0.05 & 0.39 & $0.87 * *$ & 0.05 \\
\hline LTC BTC & 0.58 & 0.27 & 0.07 & 0.98 & 0.99 & 0.86 & 0.53 & 0.18 & 0.18 & 0.84 & 1.19 & 0.46 \\
\hline XLM BTC & 0.12 & 0.10 & 0.00 & 0.32 & 1.04 & 0.91 & 0.31 & 0.14 & 0.07 & 0.51 & $0.85 *$ & 0.09 \\
\hline XMR BTC & 0.15 & 0.11 & -0.01 & 0.33 & 0.95 & 0.69 & 0.37 & 0.14 & 0.09 & 0.59 & $0.67 * * *$ & 0.00 \\
\hline DASH BTC & 0.12 & 0.12 & 0.00 & 0.38 & 1.05 & 0.88 & 0.42 & 0.21 & 0.01 & 0.72 & $0.94 *$ & 0.09 \\
\hline XEM BTC & 0.08 & 0.06 & 0.01 & 0.22 & 0.92 & 0.72 & 0.25 & 0.12 & 0.06 & 0.48 & $0.75 * * *$ & 0.01 \\
\hline BTS BTC & 0.07 & 0.10 & -0.01 & 0.34 & 0.97 & 0.91 & 0.28 & 0.11 & 0.10 & 0.45 & $0.78 * *$ & 0.02 \\
\hline XRP ETH & 0.21 & 0.18 & 0.01 & 0.55 & 1.03 & 0.74 & 0.32 & 0.17 & 0.16 & 0.73 & $0.81 * *$ & 0.05 \\
\hline LTC ETH & 0.26 & 0.56 & -0.42 & 1.44 & 1.16 & 0.76 & 0.57 & 0.31 & 0.27 & 1.25 & $0.73 * * *$ & 0.01 \\
\hline XLM ETH & 0.22 & 0.23 & 0.04 & 0.67 & 1.03 & 0.95 & 0.44 & 0.20 & 0.10 & 0.77 & $0.68 * * *$ & 0.00 \\
\hline XMR ETH & 0.29 & 0.26 & 0.10 & 0.77 & 1.02 & 0.88 & 0.54 & 0.16 & 0.21 & 0.78 & 0.85 & 0.13 \\
\hline DASH ETH & 0.34 & 0.35 & 0.11 & 0.94 & 0.82 & 0.27 & 0.64 & 0.21 & 0.22 & 0.93 & $0.69 * * *$ & 0.00 \\
\hline XEM ETH & 0.15 & 0.18 & 0.03 & 0.42 & 0.92 & 0.83 & 0.40 & 0.12 & 0.18 & 0.60 & $0.98 *$ & 0.09 \\
\hline BTS ETH & 0.34 & 0.28 & 0.10 & 0.81 & 0.95 & 0.94 & 0.40 & 0.17 & 0.20 & 0.74 & $0.75 * *$ & 0.02 \\
\hline
\end{tabular}

